\title{
Biotite supports long-range diffusive transport in dissolution-precipitation creep in halite through small porosity fluctuations
}

\author{
Berit Schwichtenberg ${ }^{1}$, Florian Fusseis ${ }^{1}$, Ian B. Butler ${ }^{1}$, and Edward Andò ${ }^{2}$ \\ ${ }^{1}$ The University of Edinburgh, School of Geosciences, Edinburgh, UK \\ ${ }^{2}$ Université des Alpes, CRNS, Laboratoire 3SR, Grenoble, France
}

Correspondence: Berit Schwichtenberg (berit.schwichtenberg@outlook.com)

Received: 14 June 2021 - Discussion started: 21 June 2021

Revised: 1 November 2021 - Accepted: 3 November 2021 - Published: 10 January 2022

\begin{abstract}
Phyllosilicates are generally regarded to have a reinforcing effect on chemical compaction by dissolutionprecipitation creep (DPC) and thereby influence the evolution of hydraulic rock properties relevant to groundwater resources and geological repositories as well as fossil fuel reservoirs. We conducted oedometric compaction experiments on layered $\mathrm{NaCl}$-biotite samples to test this assumption. In particular, we aim to analyse slow chemical compaction processes in the presence of biotite on the grain scale and determine the effects of chemical and mechanical feedbacks. We used time-resolved (4-D) microtomographic data to capture the dynamic evolution of the porosity in layered $\mathrm{NaCl}-\mathrm{NaCl} /$ biotite samples over 1619 and $1932 \mathrm{~h}$ of compaction. Percolation analysis in combination with advanced digital volume correlation techniques showed that biotite grains influence the dynamic evolution of porosity in the sample by promoting a reduction of porosity in their vicinity. However, the lack of preferential strain localisation around phyllosilicates and a homogeneous distribution of axial shortening across the sample suggests that the porosity reduction is not achieved by pore collapse but by the precipitation of $\mathrm{NaCl}$ sourced from outside the $\mathrm{NaCl}$-biotite layer. Our observations invite a renewed discussion of the effect of phyllosilicates on DPC, with a particular emphasis on the length scales of the processes involved. We propose that, in our experiments, the diffusive transport processes invoked in classical theoretical models of DPC are complemented by chemo-mechanical feedbacks that arise on longer length scales. These feedbacks drive $\mathrm{NaCl}$ diffusion from the marginal pure $\mathrm{NaCl}$ layers into the central $\mathrm{NaCl}$-biotite mix-
\end{abstract}

ture over distances of several hundred micrometres and several grain diameters. Such a mechanism was first postulated by Merino et al. (1983).

\section{Introduction}

Chemically controlled compaction influences groundwater resources, geological waste repositories and $\mathrm{CO}_{2}$ sequestration as well as fossil fuel reservoirs. One of the major processes involved in chemical compaction in the Earth's upper crust is dissolution-precipitation creep (DPC), a diagenetic and low-grade metamorphic deformation process that significantly contributes to cementation and the reduction of porosity in sedimentary rocks (Rutter, 1983; Green, 1984; Tada and Siever, 1989; Gratier et al., 2013). Due to its impact on the diagenetic evolution of sediments, it is crucial to study how DPC contributes to the dynamic change of hydraulic rock properties during compaction.

DPC describes a sequential chemo-mechanical process in a non-equilibrium system consisting of a solid phase and its associated fluid under non-hydrostatic pressure conditions (Rutter, 1983; Gratier et al., 2013). The three successive steps in the sequence are (i) dissolution of material at stressed grain contacts, (ii) diffusive mass transport through an intergranular fluid and (iii) local reprecipitation of dissolved material at low-stress sites (e.g. open pores, veins) (Rutter, 1983; Tada and Siever, 1989; Gratier et al., 2013).

Phyllosilicates have been recognised to have a reinforcing effect on the dissolution process (e.g. Heald, 1956; Weyl, 
1959; Gratier, 1987) and act as loci for enhanced DPC. Whether this is due to enhanced reaction kinetics or effective transport pathways is still under debate (Gratier, 1987) and may depend on the rate-controlling process. Macente et al. (2018) explored this effect using time-resolved X-ray microtomography to document chemical compaction in $\mathrm{NaCl}-$ biotite mixtures. They found that the increased porosity loss in the biotite-bearing layer did not lead to an increased strain localisation. These observations pointed towards infilling of porosity with material sourced outside the biotite-bearing layer rather than pore collapse, suggesting long-scale diffusive transport of dissolved $\mathrm{NaCl}$.

Reviewing diffusive transport during DPC shows that in theory four pathways for material transport need to be considered. On the one hand, there is intragranular NabarroHerring (Herring, 1950) and Coble creep (Coble, 1963), and on the other hand, diffusion through a free fluid either within grain boundaries or the open pore space (Durney, 1976; McClay, 1977). While the intragranular diffusion mechanisms are activated at elevated temperatures (Raj, 1982), it is commonly accepted that diffusive transport during lowtemperature DPC occurs through an intergranular fluid film along grain boundaries (e.g. Raj, 1982; Rutter, 1983; Gratier, 1987). Herein, transport distances do not exceed the grain size and dissolution sites are locally connected to precipitation sites (Raj, 1982; Gratier, 1987; Groshong Jr., 1988; Croize et al., 2013; Gratier et al., 2013). However, theoretical approaches (Durney, 1972, 1976; Merino et al., 1983; Lehner, 1995; Gundersen et al., 2002) as well as field evidence (Mimran, 1977; Buxton and Sibley, 1981) challenge this interpretation and suggest that long-distance diffusive transport in the open pore space needs to be considered as well.

Very few experimental data document the transport length scales of DPC. In this contribution, we build upon the work of Macente et al. (2018), and report the outcomes of further experiments on analogue samples of $\mathrm{NaCl}$, using an improved experimental setup and advanced analysis protocols for our time-resolved X-ray microtomography data. In contrast to Macente et al. (2018), who emphasise the impact of phyllosilicates upon the evolving porosity, our aim was to qualitatively determine length scales of diffusive transport in a dynamically evolving porosity during DPC and compare the results to existing transport models. The results of our experiments show that the diffusive transport length scales of DPC may exceed the grain scale without the contribution of advective transport, a phenomenon that has not been observed experimentally yet.
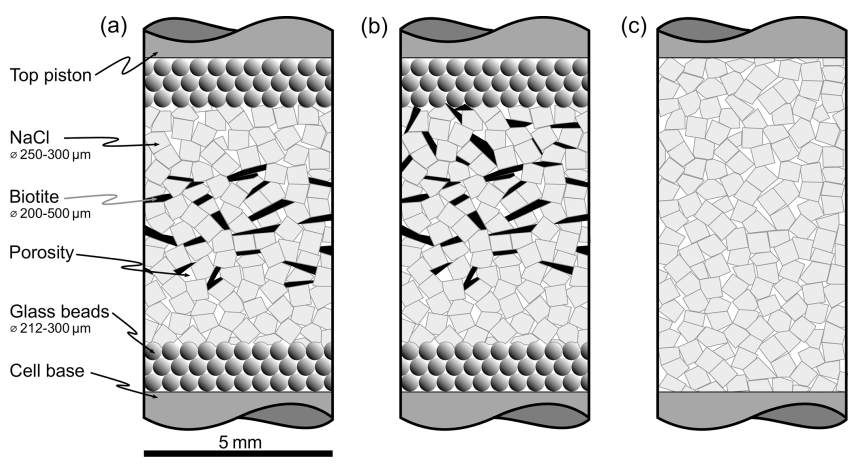

Figure 1. Schematic sketches of sample configurations of (a) the $\mathrm{NaCl}$-biotite- $\mathrm{NaCl}$ sample (SBS), (b) the $\mathrm{NaCl}$-biotite sample (SB) and (c) the pure $\mathrm{NaCl}$ reference sample (S) before deformation. Different shades of grey depict the single components but are not related to their appearance in the tomography scans. White angular patches represent the brine saturated pore space with arbitrary distribution of shape and size, light grey angular to square objects are cubic grains of analytical-grade $\mathrm{NaCl}$ with a sieved grain size of $250-300 \mu \mathrm{m}$, and black elongated angular shapes are biotite grains of $200-500 \mu \mathrm{m}$ size. At the top and bottom of the samples in panels (a) and (b), dark grey circles describe acid-washed glass beads of 212-300 $\mu \mathrm{m}$ diameter, which were inserted as a chemically inert layer. The original samples have a diameter of $5 \mathrm{~mm}$; note that the sketches are not to scale.

\section{Materials and methods}

\subsection{Introduction}

Aggregates containing sodium chloride $(\mathrm{NaCl})$ and biotite were used to analyse the effect of DPC in granular materials. As previous studies have shown (e.g. Spiers et al., 1990; Peach, 1991; Bons and Urai, 1994; Macente, 2017; Macente et al., 2018), analogue materials are suitable to study deformation mechanisms at moderate $P-T$ conditions in experiments of a tractable duration, and the results can be extrapolated to natural conditions. We chose $\mathrm{NaCl}$ as its solubility at low pressures and temperatures is high compared to other constituent minerals of sedimentary rocks (Trurnit, 1968) and it has previously been used for compaction experiments at room temperature (Spiers and Schutjens, 1990; Schutjens and Spiers, 1999; Renard et al., 2001, 2004; Gratier et al., 2013). It is further considered as a host rock for geological nuclear waste repositories (e.g. Hansen and Leigh, 2011; von Berlepsch and Haverkamp, 2016), and its deformation behaviour is well characterised (Carter and Hansen, 1983; Urai et al., 2008).

\subsection{Sample preparation}

Two layered samples and one homogeneous sample were prepared for oedometric compaction experiments in low Xray attenuation oedometer cells (Fig. 1). A detailed description of the cell design can be found in Macente (2017). The 
first sample (SBS) contained a central $\mathrm{NaCl}$-biotite layer and two adjoining layers of pure $\mathrm{NaCl}$ as well as two layers of glass beads. The latter maintain permeability at the sample ends. For the second sample (SB), we increased the ratio of the $\mathrm{NaCl}$-biotite layer and removed the top $\mathrm{NaCl}$ layer. A third pure $\mathrm{NaCl}$ sample (S) served as a reference.

Masses for all components were calculated to meet the dimensions of cylindrical samples with $5 \mathrm{~mm}$ diameter and a desired starting height of $8 \mathrm{~mm}$. For the unconsolidated samples, an initial porosity of $\sim 40 \%$ was assumed which was also included into the calculation. The absolute heights of the samples were determined after loading the oedometers with the granular aggregate. Analytical-grade $\mathrm{NaCl}$ and natural biotite were chosen as main components for the samples, as the difference in the X-ray attenuation results in a sufficient contrast in the reconstructed $\mu \mathrm{CT}$ data. The granular $\mathrm{NaCl}$ was sieved to a grain size of $250-300 \mu \mathrm{m}$. Biotite of granodioritic origin (Lone Grove pluton, Texas, e.g. Zartman, 1964) was pre-processed by mineral separation techniques (conducted at GFZ Potsdam, who supplied the biotite mineral separate) and sieved to a grain size of $200-500 \mu \mathrm{m}$ (maximum grain diameter). Acid-washed glass beads with a diameter of 212$300 \mu \mathrm{m}$ were added as chemically inert and permeable top and base layers.

The individual sample components were introduced into the sample cell by wet loading. Saturated $\mathrm{NaCl}$ brine was injected into the bottom of the sample cell. For the two biotitebearing samples (SBS and SB) glass beads and $\mathrm{NaCl}$ were sequentially poured into the brine followed by a homogeneous slurry of $\mathrm{NaCl}$ and $20 \mathrm{wt} \%$ biotite. For the pure $\mathrm{NaCl}$ sample, dry $\mathrm{NaCl}$ (not a slurry) was poured into the injected brine. All samples were covered at the top and bottom with a disc of filter paper to prevent blockage of the fluid inlet and outlet.

After the piston was twisted into the oedometer, the samples were flushed with brine to saturate the entire pore space with fluid. At this stage, a low axial load was applied to the top piston which kept the piston in place but was balanced by the pore pressure so that the effective load remained zero.

\subsection{Experimental setup}

The experimental setup was designed to run three oedometric compaction experiments simultaneously (Fig. 2). We adopted the basic setup from Macente et al. (2018) and added a thermally insulated environment, vibration damping, pressurised fluid pumps and chemically inert glass bead layers to gain better control of parameters and establish a better characterised system. The oedometer cells as described in Macente et al. (2018) were modified by sealing the sample cell with an $\mathrm{O}$ ring around the piston in order to withstand fluid pressure of 0.5 MPa. The latter was applied in two different ways. For the SBS sample, we used Cetoni neMESYS syringe pumps feeding a fluid transfer vessel that isolated the metal-corrosive brine. The transfer vessel was composed of

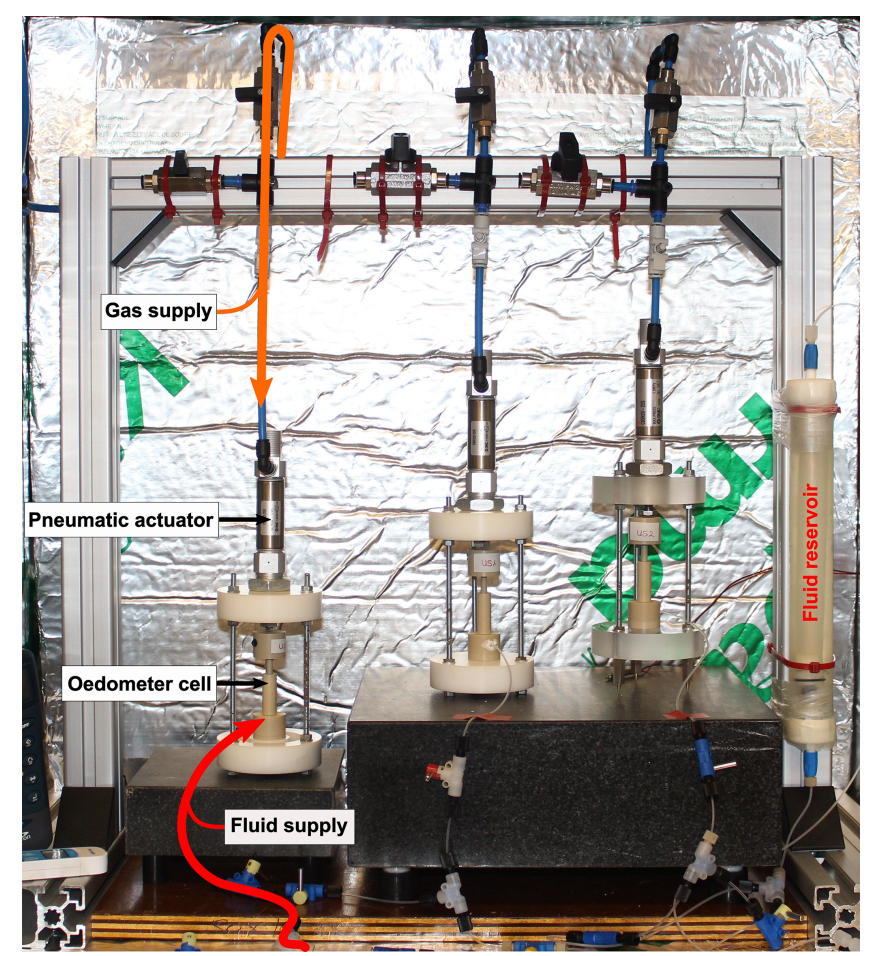

Figure 2. Experimental setup for oedometric compaction experiments conducted at the University of Edinburgh. Three samples could be loaded simultaneously. Oedometer cells contained the cylindrical samples and were confined in straining frames during deformation. The load was applied by gas-driven pneumatic actuators installed at the top of each frame. Cetoni neMESYS highpressure syringe pumps were used to supply saturated $\mathrm{NaCl}$ brine via a fluid reservoir in order to maintain a pore fluid pressure sufficient to suppress gas bubbles in the samples. For the second experimental suit we replaced the fluid reservoir and high-pressure pump with a brine-filled syringe that was driven by another pneumatic actuator (not shown here). The oedometer cells were placed on acoustically dampened gabbro blocks to avoid external vibrations to reach the cells.

a silicone tube filled with saturated $\mathrm{NaCl}$ brine inside a pressure resistant glass column. Saturation of the brine was guaranteed by the presence of solid $\mathrm{NaCl}$ in the reservoir. For the pure $\mathrm{NaCl}$ and the $\mathrm{SB}$ samples, we used a plastic syringe that contained the corrosive brine itself and was driven by a pneumatic actuator. The experimental setup allowed maintaining a moderate pore fluid pressure to suppress gas bubbles while suppressing fluid advection.

The axial load was also applied by gas-pressure-driven pneumatic actuators when the oedometer cells were placed in loading frames following the construction of Macente (2017).

The experiments were run inside a thermally insulated box where the temperature was logged and found to be stable within $\pm 1.7^{\circ} \mathrm{C}$ over the course of the experiments. For the acquisition of microtomographic data, the oedometers were 


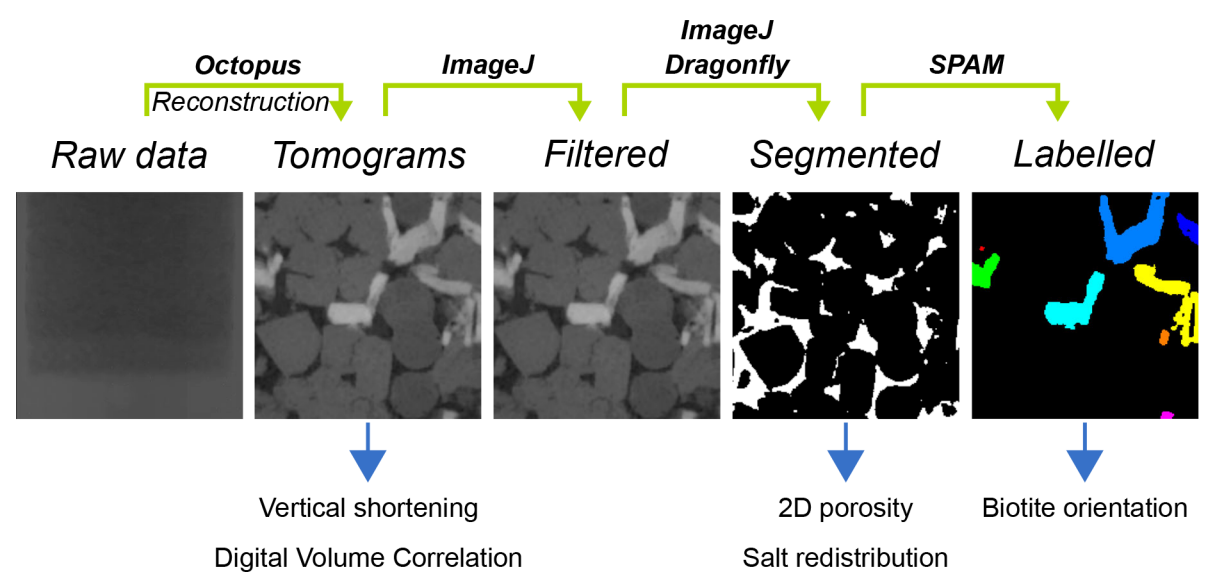

Figure 3. Workflow used for data processing. At the top, the specific software used in each processing step is given, while the information gained from the individual steps is listed below a representative 2-D slice of the particular processing result. The individual steps are based on each other going from the left (the unprocessed radiograph) to the right (highly processed data).

disconnected from the fluid and pneumatic capillaries and mounted into the microtomography scanner (see next section).

Upon initial loading, the unconsolidated granular samples were held at a constant effective load of $6.64,6.77$ and $10.5 \mathrm{MPa}$ for samples $\mathrm{S}, \mathrm{SBS}$ and $\mathrm{SB}$, respectively, for 60 min. After an initial compaction of 9\%-18\%, a reference scan was acquired of the starting aggregate.

The loading parameters were maintained throughout the experiments and consistently monitored over a total duration between 1089 and 1932 h. Following Macente (2017) and Macente et al. (2018), the conditions for the first experimental suite (SBS) were chosen to be similar which allowed comparison of the data with each other. For the second experimental suite (SB and S), the effective load was increased in order to increase the strain rate according to the rate law for diffusion-controlled DPC (Spiers et al., 2004).

\subsection{Data acquisition}

During the experiment, the samples were scanned ex situ on the X-ray microtomography instrument at the School of Geosciences, University of Edinburgh, in regular intervals (for acquisition parameters, see Table A2 in the Appendix). To enable this, the oedometers were unloaded and temporarily removed from the loading frames. In total, 19 scans (SBS sample), 10 scans (SB sample) and 5 scans (S sample) were acquired over a total duration of 1619, 1932 and $1089 \mathrm{~h}$, respectively. At the beginning, scans were collected in shorter time intervals to image the rapidly progressing deformation within the first $200 \mathrm{~h}$ of the experiment. As the compaction slowed down, the intervals between each scan were gradually extended to monitor chemical compaction processes. The time-resolved 3-D data series obtained in this way were then combined into three 4-D data sets capturing the dynamic evolution of the porosity in the different samples.

\subsection{Data processing}

After each scan, Octopus ${ }^{\circledR}$ software v. 8.9 (Dierick et al., 2004) was used to reconstruct the $\mu \mathrm{CT}$ data from the radiographic projections. The resulting stack of 2-D images, which contains a virtual representation of half of the sample, covers a volume of $5 \times 10^{3} \mu^{3}$. Each time step comprises two scans, vertically translated to cover the entire sample including the sample base and the top piston. Reconstructed image stacks were merged using the image processing software Avizo ${ }^{\circledR}$ v. 9.2. The relative shortening of the sample was calculated using

$\varepsilon_{t}=\frac{L_{0}-L_{t}}{L_{0}}$,

with the relative vertical shortening $\varepsilon_{t}$ at the time $t$, the initial sample height $L_{0}$ and the sample height $L_{t}$ at the time $t$. The height of each sample was determined from the merged $\mu \mathrm{CT}$ scans. The $\mu \mathrm{CT}$ data were prepared for analysis by pre-processing in ImageJ (Schindelin et al., 2012). An uneven background of the reconstructed images was adjusted using the background correction plugin BaSiC (Peng et al., 2017) with the regularisation parameter $\lambda_{D}=0.69$ and $\lambda_{\mathrm{F}}=1.71$ for the estimated dark-field and flat-field images, respectively. Denoising of the data was conducted by removing bright outliers (threshold of 50) of $1.5 \mathrm{px}$ and using the non-local means filter (Buades et al., 2011) with a standard deviation of $\sigma=3$ and a smoothing factor of 1 . Biotite grains and porosity were segmented as single classes from the images, applying the machine learning tool "Trainable Weka Segmentation" (Arganda-Carreras et al., 2017). The latter was also used to segment $\mathrm{NaCl}$ grains in the pure $\mathrm{NaCl}$ sample but not in the two biotite-bearing samples. Due to a lack of contrast between the grey scales of $\mathrm{NaCl}$, glass beads and the outer rims of biotite grains, it was not possible to use simple segmentation techniques. Instead we applied the 
"Deep Learning Segmentation" of Dragonfly software, version 2020.2 (Object Research Systems , ORS) to discretely segment the $\mathrm{NaCl}$. The resulting binarised image stacks were used for image analysis to quantify the porosity evolution and $\mathrm{NaCl}$ migration.

\subsubsection{Porosity measurements}

The evolving porosity was determined during compaction as two-dimensional porosity which was measured along the direction of the loading axis as the relative area of the twodimensional binarised images. The results were plotted as the porosity on the abscissa and the number of slices along the loading axis on the ordinate (Fig. 13). Errors for this analysis were determined using the probability measured in the Trainable Weka Segmentation. The absolute error of the porosity measurement was defined as the difference between the number of pixels belonging to the porosity with a certainty of $\geq 90 \%$ to the total number of porosity pixels measured from the segmented data. The absolute error is given in percent, as it refers to the porosity which itself is a relative number.

\subsubsection{NaCl redistribution measurements}

In order to quantify the amount of $\mathrm{NaCl}$ migrating within the sample, we used two different methods to isolate a pure $\mathrm{NaCl}$ signal from the rest of the sample. The first method is similar to the measurement of the 2-D porosity. For each slice along the loading axis of a microtomography scan, we discretely segmented the $\mathrm{NaCl}$ in the grey-scale image using Trainable Weka Segmentation for the pure $\mathrm{NaCl}$ sample and the Deep Learning Segmentation of Dragonfly software for both biotite-bearing samples. From the segmented data, we measured the relative area of $\mathrm{NaCl}$ in the two-dimensional image and calculated its proportion relative to the cross section of the sample. The results were plotted as relative $\mathrm{NaCl}$ content on the abscissa and the number of slices along the loading axis on the ordinate (Fig. 14).

Our second approach towards quantifying the $\mathrm{NaCl}$ redistribution in the sample was based on 3-D volumetric measurements of segmented $\mathrm{NaCl}$. The volumes of $\mathrm{NaCl}$, biotite and porosity were measured relative to a subvolume in the compacting biotite-bearing layer (for location of the subvolume, see Fig. A1 in the Appendix). We selected the subvolumes at fixed locations within the biotite-bearing domains of both samples that mimic the compaction of the respective layer. The extent of the subvolume parallel to the loading axis was defined by two prominent biotite grains at the top and bottom of each biotite-bearing layer which were easy to identify with progressing compaction of the sample. Perpendicular to that dimension, the base of the subvolume was chosen as a $500 \mathrm{px} \times 500 \mathrm{px}$ square in the centre, which is representative of the sample but excludes the contact area of the sample to the cell. This approach allowed us to measure the evolution of the $\mathrm{NaCl}$ volume within the biotite-bearing
Table 1. Correlation parameters used to conduct digital volume correlation for different data series. The correlation window size, usually used in digital image correlation (DIC) applications, corresponds to $1+2 \times$ the half window size given in the table. The threshold value is simply implemented to skip correlation windows placed outside the sample based on their mean grey value.

\begin{tabular}{lrrr}
\hline DVC parameters & SBS & SB & S \\
\hline Correlation half window size & 30 & 30 & 30 \\
Measurement point spacing & 15 & 15 & 15 \\
Low-grey-level threshold & 4000 & 5000 & 16000 \\
\hline
\end{tabular}

layer with progressing deformation, with biotite acting as an internal standard. The results were plotted as $\mathrm{NaCl}$ volumes relative to a decreasing subvolume in the compacting biotitebearing layer (Fig. 15).

\subsection{Digital volume correlation}

Digital volume correlation (DVC) was used to quantify deformation on the grain scale between pairs of consecutive 3$\mathrm{D} \mu \mathrm{CT}$ data sets using the Python packages SPAM (Stamati et al., 2020) and TomoWarp2 (Tudisco et al., 2017). While SPAM calculates the displacement field between two data sets, TomoWarp2 uses the latter as an input to calculate the strain field. In a first step, a grid of regularly spaced measurement points was defined in the reference image. Each of these points is the centre point of a cubic correlation window. A corresponding cube in the deformed image was transformed with a homogeneous deformation function in order to minimise a sum-of-squared-differences error function. The correlation parameters were individually tuned for each data series and are documented in Table 1. The DVC analysis was completed by strain determination. A finite strain tensor $U$ and its first two invariants - the volumetric strain (Eq. 3) and the deviatoric strain (Eq. 4) - were calculated from the locally measured displacement component of the deformation function.

$U=U_{\text {isotropic }} \cdot U_{\text {deviatoric }}$

While the isotropic component of the strain tensor is equal to the volumetric strain and describes a change in volume, the deviatoric strain describes the deformation at constant volume.

$U_{\text {isotropic }}=J^{1 / 3} \cdot \mathbf{I}$

$U_{\text {deviatoric }}=\frac{1}{J^{1 / 3}} \cdot U$,

where $U_{\text {isotropic }}$ is the isotropic or volumetric strain, and $U_{\text {deviatoric }}$ the deviatoric strain. I is the identity matrix, $J$ the determinant of the strain tensor, and its exponent refers to the dimension of the problem which is three-dimensional in this case. It is important to note that the given definition of 
strain applies to strain on the grain scale only and needs to be differentiated from the 1-D macro-strain that reflects the vertical shortening and compaction of the bulk samples.

The mean strain rates were obtained by dividing the magnitude of the strain tensor by the time (in seconds) between two analysed data sets.

With label analysis, also implemented in SPAM, we determined the rotation and rearrangement of single biotite grains with progressing deformation based on labelled and binarised data sets. For each microtomography scan, we segmented the biotite grains as described in Sect. 2.5 and applied a watershed algorithm to separate the grains into individual particles with an allocated label. Further, we calculated the eigenvalues and eigenvectors from each particle's moment of inertia, which is in the case of biotite directly related to the shape and orientation of the particle. The orientations are represented as maximum eigenvectors perpendicular to the basal planes of the grains and plotted as densities in Lambert projections with the vertical loading axis in the centre of the plot (Fig. 7).

\section{Results}

\subsection{Bulk compaction behaviour}

\subsubsection{Vertical shortening}

The bulk compaction of the samples was monitored as vertical shortening and compaction rate over a total duration of $1089 \mathrm{~h}, 1619 \mathrm{~h}$ and $1932 \mathrm{~h}$, for the reference sample (S), the SBS and the SB samples, respectively.

All three samples showed a non-linear decrease in height. The SBS sample accommodated a total strain of $\sim 25 \%$ over $1619 \mathrm{~h}$ of compaction. Initially, the sample shortened by $\sim 9 \%$ within the first $16 \mathrm{~h}$ of compaction, resulting in a steep gradient of the compaction curve, while in the following interval the compaction rate gradually decreased and stabilised after about $280 \mathrm{~h}$, indicating apparent steady-state deformation (Fig. 4). The compaction rates of the SB sample and the pure $\mathrm{NaCl}$ reference sample followed similar trends. The SB sample accommodated a total vertical shortening of $\sim 26 \%$ after $1932 \mathrm{~h}$ of which $\sim 11 \%$ occurred within the first $19 \mathrm{~h}$ of deformation. This sample reached apparent steady-state deformation after about $324 \mathrm{~h}$.

As the compaction of the reference sample was stopped after $1089 \mathrm{~h}$, the total shortening of this sample was with $\sim 17 \%$, lower than the total shortening of the biotite-bearing samples. At comparable compaction stages of 1020 and $1060 \mathrm{~h}$, for the SBS and SB sample, respectively, the difference between the reference and the biotite-bearing samples was approximately $\sim 10 \%$ (Fig. $4 \mathrm{a}$ ). It is notable that the final scans in all three experiments were acquired before the compaction ceased.
Analysis of the bulk strain rates $(\dot{\varepsilon})$ with progressing compaction support these findings. On a double logarithmic scale (Fig. 4b), strain rates for all three samples decreased approximately linearly and dropped in total by 2 orders of magnitude from $\sim 10^{-6}$ to $\sim 10^{-8} \mathrm{~s}^{-1}$. Within the first $200 \mathrm{~h}$ of compaction, the strain rates decreased by 1 order of magnitude. The apparent steady-state deformation interval was characterised by a constant strain rate gradient of $\sim-5 \times{ }^{-11} \mathrm{~s}^{-1}$. Linear regressions for the three strain rates over time $(t)$ have the form of

$\dot{\varepsilon}=t^{-1.09} \times e^{-10.80}$
$\dot{\varepsilon}=t^{-1.26} \times e^{-9.81}$
$\dot{\varepsilon}=t^{-1.01} \times e^{-11.16}$,

for the SBS, SB and pure $\mathrm{NaCl}$ sample, respectively.

\subsubsection{Microstructures and compaction accommodation}

Vertical slices through the geometrical centre of $\mu \mathrm{CT}$ data illustrate the evolution of the microstructure (Fig. 5). In the biotite-bearing samples' porosity reduction, a change of the cubic habit of the $\mathrm{NaCl}$ grains and the establishment of flat interphase boundaries between $\mathrm{NaCl}$ and biotite grains can be observed over 100 and $60 \mathrm{~h}$ for the SBS and the SB sample, respectively. Within the biotite-bearing layers, characteristic evidence for DPC (dissolution leading to grain indentation and reprecipitation of dissolved matter) was enhanced along phase boundaries (Figs. 5a-h and 6a-j). However, the pure $\mathrm{NaCl}$ layers as well as the $\mathrm{NaCl}$ reference sample showed, to a smaller extent, similar dissolution structures at later compaction stages (Fig. 6k-n). The efficiency of the process becomes obvious on the grain scale (Fig. 6a-j and animation $\mathrm{S} 1$ in the Supplement, which shows a single $\mathrm{NaCl}$ grain enclosed by two biotite grains with progressing deformation). We found that the orientation of the enclosing biotite grains did not change significantly as the volume of the $\mathrm{NaCl}$ grains was reduced. We calculated the vertical shortening of the single $\mathrm{NaCl}$ grain to be $\sim 26 \%$ in the SBS sample and $\sim 22 \%$ in the SB sample, which is similar to the shortening calculated for the bulk biotite-bearing samples (see Sect. 3.1.1).

The orientation of the maximum eigenvector of individual biotite grains was plotted in Lambert projections (Fig. 7; see the Appendix for an explanation on how to read a Lambert projection). For both biotite-bearing samples, areas with a high density of data points were located close to the centre of the plots, revealing that the maximum eigenvectors of single biotite grains were orientated vertically and did not significantly rotate away from the vertical loading axis after an instantaneous mechanical rearrangement of the grains.

Our analysis showed that the compaction was accommodated throughout the samples, independent of their composition. Only the glass bead layers did not accommodate further compaction after an initial mechanical rearrangement. 


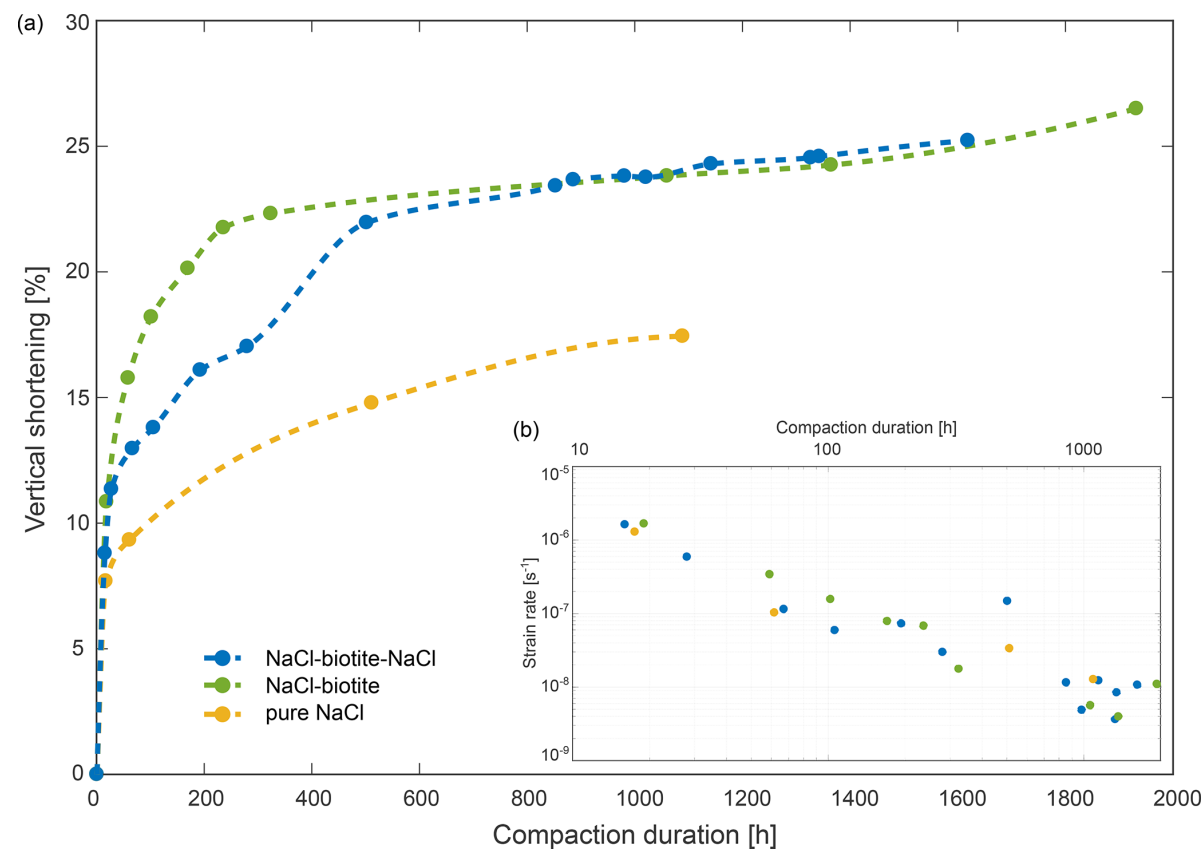

Figure 4. Bulk compaction curves (a) and strain rates (b) derived from $\mu \mathrm{CT}$ data for the three samples, SBS in blue, SB in green and pure $\mathrm{NaCl}$ in yellow. Panel (a) shows the vertical shortening of the samples with progressing deformation. We interpret the non-linearity of the curves as the transition from a loosely packed aggregate where mechanical compaction significantly contributes to the strain rate, to an interlocked aggregate dominated by chemical compaction. Note that all three samples show a similar trend with apparent steady-state deformation established after $\sim 250 \mathrm{~h}$. Data points were connected by spline interpolation. In panel (b), we plotted the corresponding bulk strain rates over the compaction duration.

Figure 8 shows the vertical displacement rate of the biotitebearing layer and the bulk sample for different increments of progressing deformation for the two biotite-bearing samples. The time intervals which correspond to the individual increments are listed in the table below the plot. At the beginning of the experiment, the rate of both bulk samples was elevated compared to the biotite-bearing layers. However, as compaction approached an apparent steady state, the vertical displacement rates of the biotite-bearing layer and the bulk sample became comparable and both asymptotically approached a value of zero.

\subsection{Strain analysis}

DVC was used to analyse a locally resolved strain field and associated strain rates. Figures 9-11 show the deviatoric strain and volumetric strain for the three samples at different stages during the deformation. Deviatoric strain maxima in the two biotite-bearing samples (Figs. 9 and 10) were located within the biotite-bearing layers but not exclusively. In both samples, pure $\mathrm{NaCl}$ domains adjacent to the biotite-bearing layer were also affected by higher strains. Note that the activity in the top $\mathrm{NaCl}$ layer of the SBS sample seems to be lower than in the bottom $\mathrm{NaCl}$ layer of the same sample. In addition to that, the deviatoric strain maxima in the SBS sample correlate with negative volumetric strain (compaction). A simi- lar correlation was found in the SB sample. Here as well, no layer-specific strain pattern with strain maxima located in the biotite-bearing layer emerged. Further, the strain distribution in the biotite-bearing samples was comparable to the one observed in pure $\mathrm{NaCl}$ reference sample. Here, deviatoric and volumetric strain maxima were homogeneously distributed within the bulk sample (Fig. 11). Overall, the dominating character of the volumetric strain was negative in all three samples, indicating compaction.

Furthermore, we calculated average strain rates from the locally resolved strains by dividing each calculated strain value by the time interval length given in seconds. The results are displayed in Table 2 and show an overall decreasing trend in all three samples. In the two biotite-bearing samples, deviatoric strain rate maxima were homogeneously distributed, independent of the layer composition. Comparison of these results to the pure $\mathrm{NaCl}$ sample showed no major difference. The observed rates are comparable to the bulk strain rates (see Sect. 3.1.1).

In order to locate the strain maxima in 3-D and compare them to the position of the biotite grains, we plotted the deviatoric and volumetric strain data of the biotite-bearing sample SBS on top of the segmented biotite data (Fig. 12). This showed that in the early stages of our experiment, deviatoric strain maxima corresponded to the location of biotite grains as well as open pore space and pure $\mathrm{NaCl}$ clusters. Later on 

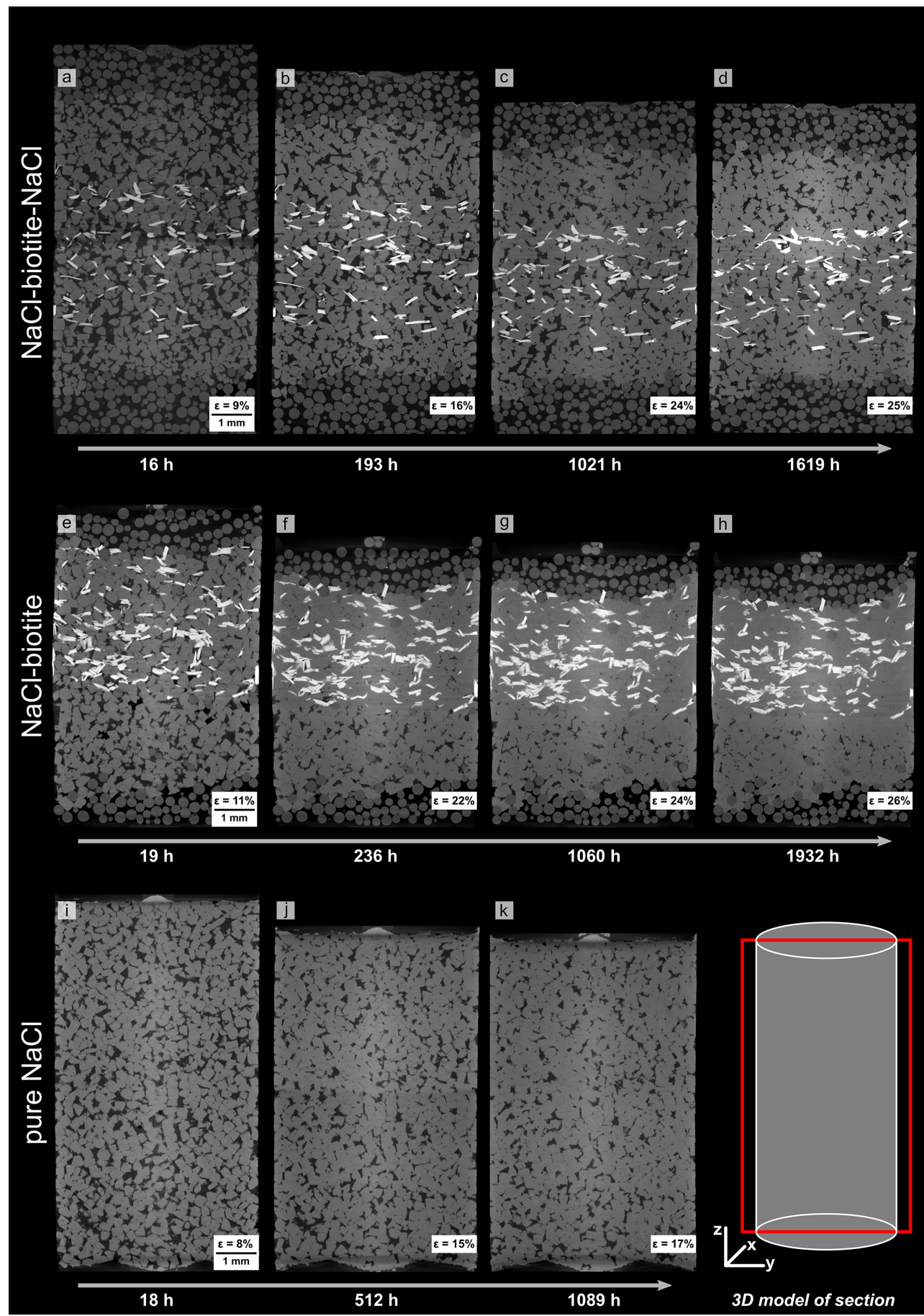

Figure 5. Vertical slices through absorption $\mu \mathrm{CT}$ scans at different stages of compaction. The 3-D model in the lower right corner shows the location of the section within the bulk samples. Different shades of grey refer to different phases present in the samples (in black: brinefilled pore space, dark grey: glass beads, grey: $\mathrm{NaCl}$ grains and light grey: biotite). The top and middle rows show the $\mathrm{NaCl}-$ biotite samples SBS (a-d) and SB (e-h), respectively, the bottom row displays the pure $\mathrm{NaCl}$ sample (i-k). Panels (b), (f) and (j) show first signs of porosity reduction and indentation of $\mathrm{NaCl}$ grains which we interpret as indicators for active dissolution-precipitation creep and which is continuing throughout the experiment. Note that the final scan of the SB sample (h) shows no remaining porosity in the biotite-bearing layers, whereas it is still clearly visible in the SBS (d) and the pure $\mathrm{NaCl}$ sample (k). 


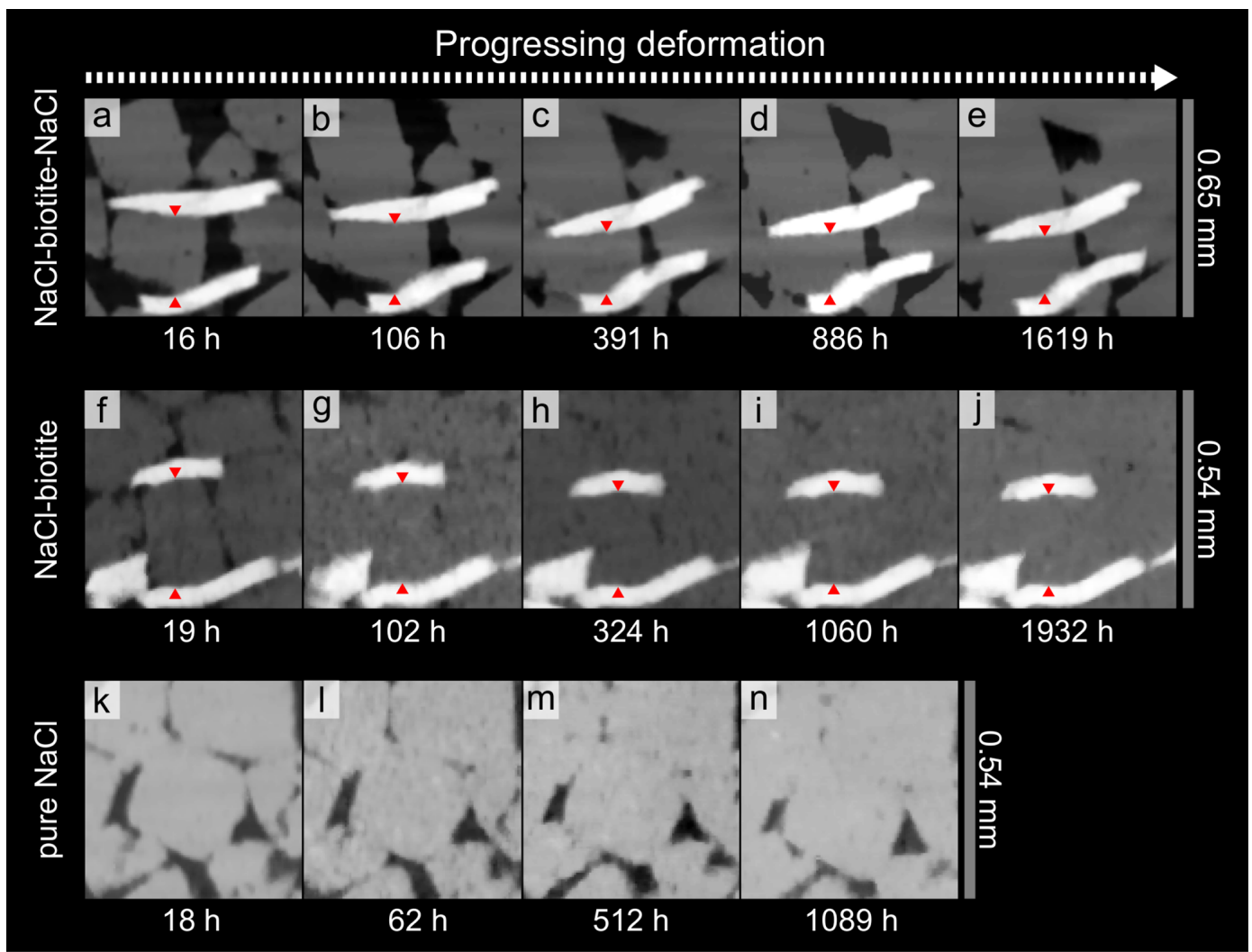

Figure 6. Sequence of time steps showing active dissolution-precipitation creep at the interphase boundaries of a $\mathrm{NaCl}$ grains with two biotite grains in the SBS (a-e) and SB samples (f-j). While the sizes of the $\mathrm{NaCl}$ grains are reduced without showing any signs of brittle deformation, interphase contacts with the mica become flattened, indicating dissolution of $\mathrm{NaCl}$. Comparison of panels (a) and (e) and (f) and (j) shows that the vertical strain accommodated by the $\mathrm{NaCl}$ grains is $\sim 26 \%$ in the SBS sample and $\sim 22 \%$ in the SB sample. Note that the biotite grains have experienced only little rotation during deformation, although 1603 and $1913 \mathrm{~h}$ of compaction are in between the first and the last images. In the SBS sample, the rotation of the top biotite grain occurs prior to the apparent steady state. Red arrows are used as markers for strain calculations. The pure $\mathrm{NaCl}$ sample (k-n) on the other hand shows less activity of DPC. However, here as well contacts between grains are flattened and pore space reduced.

Table 2. Mean strain rates derived from image correlation.

\begin{tabular}{lrrr}
\hline Sample & Time $[\mathrm{h}]$ & Deviatoric strain rate $\left[\mathrm{s}^{-1}\right]$ & Volumetric strain rate $\left[\mathrm{s}^{-1}\right]$ \\
\hline SBS & $28-67$ & $2.0 \times 10^{-7}$ & $-7.0 \times 10^{-8}$ \\
& $193-280$ & $4.8 \times 10^{-8}$ & $-3.3 \times 10^{-8}$ \\
& $1343-1619$ & $1.6 \times 10^{-8}$ & $-9.1 \times 10^{-10}$ \\
\hline SB & $19-59$ & $3.8 \times 10^{-7}$ & $-3.6 \times 10^{-7}$ \\
& $236-324$ & $3.3 \times 10^{-8}$ & $-2.3 \times 10^{-8}$ \\
& $1365-1932$ & $7.7 \times 10^{-9}$ & $-3.3 \times 10^{-8}$ \\
\hline S & $18-62$ & $2.2 \times 10^{-7}$ & $-1.8 \times 10^{-7}$ \\
& $62-512$ & $4.3 \times 10^{-8}$ & $-1.2 \times 10^{-8}$ \\
& $512-1089$ & $1.9 \times 10^{-8}$ & $-1.6 \times 10^{-8}$ \\
\hline
\end{tabular}



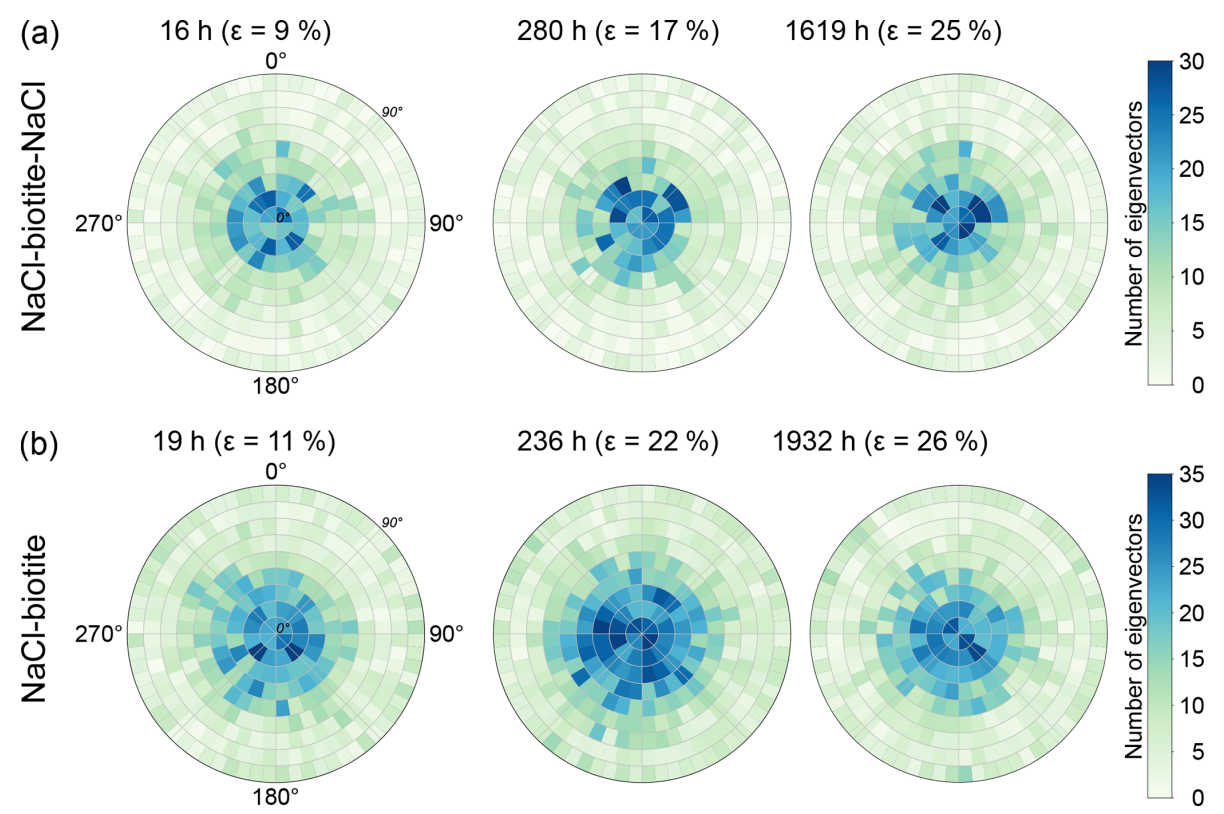

Figure 7. Density plots of the eigenvector of biotite grains in (a) the SBS and (b) the SB sample. The maximum eigenvectors are plotted as densities in Lambert projections perpendicular to the basal planes of the grains. The vertical loading axis is in the centre of the plot. The rings around the central point give the angle between the vertical loading axis and the eigenvector, ranging from $0^{\circ}$ in the centre to $90^{\circ}$ at the outer margin. High densities of eigenvectors are displayed in blue, whereas lower densities are displayed in green. Note that the biotite grains do not change their orientation significantly with progressing deformation. For both samples, the highest densities can be found in proximity to the central axis indicating that the majority of grains is oriented horizontally within the samples. Numbers of grains measured are from left to right for (a) 1836, 1833 and 1986 and for (b) 3066, 3836 and 3007, which correspond to 20 wt\% of biotite in the respective layer.

this correlation still existed but was less distinctive. However, local minima and maxima of the volumetric strain did not correlate with the position of biotite grains.

\subsection{Porosity evolution}

A two-dimensional analysis of the porosity in each slice along the loading axis shows that the two biotite-containing samples developed a characteristic pattern in their porosity distribution with progressing deformation. In both samples, the maximum loss of porosity correlates with the location of the biotite-bearing layer (Fig. 13b and c). Whereas in sample SBS the minimum porosity did not fall below $\sim 10 \%$ even after $1619 \mathrm{~h}$, we observed the compartmentalisation of SB into a low- $(\phi \leq 2 \%)$ and a high-porosity $(\phi \sim 15 \%)$ zone after $236 \mathrm{~h}$ (Fig. 13b).

In the pure $\mathrm{NaCl}$ sample, the porosity decreased homogeneously and did not fall below $\sim 10 \%$ by the end of the experiment (Fig. 13a). Errors for the analyses were determined as $1.7 \%-6.9 \%$ for the SBS sample, $1.2 \%-8.4 \%$ for the SB sample and $3.8 \%-7.3 \%$ for the pure $\mathrm{NaCl}$ sample.

\section{4 $\mathrm{NaCl}$ redistribution}

Similar to the 2-D porosity, the $\mathrm{NaCl}$ content was determined in each slice along the loading axis. The evolution of the relative $\mathrm{NaCl}$ distribution in the three samples is shown in
Table 3. Starting porosity of individual layers after $1 \mathrm{~h}$ of compaction.

\begin{tabular}{llll}
\hline & SBS & SB & S \\
\hline $\mathrm{NaCl}$ & $\begin{array}{l}\text { top: } 30.8 \% \\
\text { bottom: } 33.0 \%\end{array}$ & $25.3 \%$ & $27.0 \%$ \\
\hline Biotite & $30.8 \%$ & $24.3 \%$ & - \\
\hline
\end{tabular}

Fig. 14. In the SBS sample, the pure $\mathrm{NaCl}$ layers gained $\sim 14 \%$ and $\sim 16 \%$ for the bottom and top layer, respectively (Fig. 14a). A similar trend could be observed in the SB sample (Fig. 14b). Here, the pure $\mathrm{NaCl}$ layer showed an increase of $\mathrm{NaCl}$ by $\sim 13 \%$ and the amount of $\mathrm{NaCl}$ at the $\mathrm{NaCl}$-biotite interface increased by $\sim 15 \%$ (Fig. 14b). Notable shoulders formed at the interfaces between the pure $\mathrm{NaCl}$ and the $\mathrm{NaCl}$-biotite layers. In addition to that, no $\mathrm{NaCl}$ precipitated in the glass bead layers. The pure $\mathrm{NaCl}$ sample on the other hand showed a homogeneous increase of the $\mathrm{NaCl}$ content per slice by $\sim 13 \%$ throughout the bulk sample. This is comparable to the pure $\mathrm{NaCl}$ layer in the $\mathrm{SB}$ sample. Errors for the analyses were determined as $1.4 \%-$ $4.5 \%$ for the SBS sample, $2.7 \%-5.3 \%$ for the SB sample and $5.8 \%-7.5 \%$ for the pure $\mathrm{NaCl}$ sample. 
(a) $\mathrm{NaCl}$-biotite- $\mathrm{NaCl}$ sample

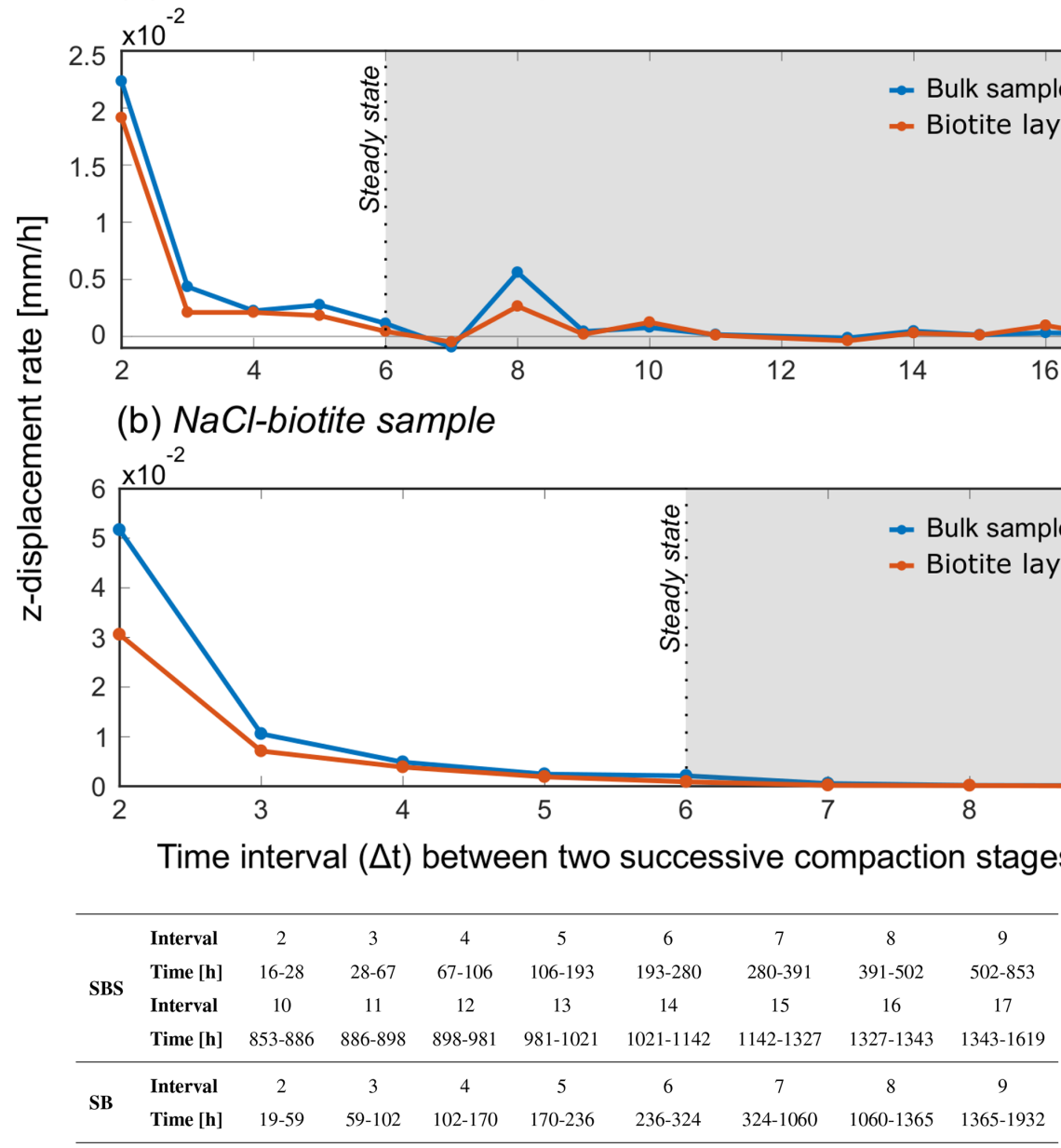

Figure 8. The graph shows the vertical displacement rate of the bulk sample and the biotite-bearing layer for different increments of progressing deformation over the duration of the experiments. Panel (a) contains data from the SBS sample and (b) from the SB sample. Before the apparent steady-state deformation the bulk samples compact faster than the biotite-bearing layer. This trend continues into the apparent steady state (grey-shaded area) although both rates become comparable to each other, indicating that the biotite-bearing layer is not compacting faster than the bulk sample.

Table 4. Salt content of the samples derived from image analysis and compared to the initial weight by mass balance.

\begin{tabular}{lcrl}
\hline Time $[\mathrm{h}]$ & $\begin{array}{c}\text { Mass calculated from } \\
\text { binary data [g] }\end{array}$ & $\begin{array}{l}\text { Deviation from } \\
\text { initial mass [\%] }\end{array}$ & $\begin{array}{l}\text { Abs. error from } \\
\text { segmentation [\%] }\end{array}$ \\
\hline SBS sample & & & \\
\hline 16 & 0.231 & -3.3 & 1.69 \\
193 & 0.225 & -5.7 & 1.77 \\
1619 & 0.219 & -8.2 & 4.47 \\
\hline SB sample & & & \\
\hline 19 & 0.176 & 0.5 & 2.91 \\
170 & 0.164 & -6.4 & 3.76 \\
1932 & 0.163 & -6.8 & 5.25 \\
\hline S sample & & & \\
\hline 18 & 0.304 & -7.9 & 6.9 \\
512 & 0.309 & -6.4 & 5.9 \\
1089 & 0.322 & -2.5 & 5.8 \\
\hline
\end{tabular}

Figure 15 shows volumetric analyses that determine the relative proportions of $\mathrm{NaCl}$, pores and biotite in the biotitebearing layers. In these analyses, biotite acts as an insoluble internal standard. Errors for the measurements were determined from the accuracy of the AI segmentation and are represented by a shaded area around the line plot. Both samples show that, while the biotite content is indeed constant within the analysed subvolumes, the relative reduction of porosity is compensated by a relative increase in the $\mathrm{NaCl}$ content in these volumes. In the SBS sample, just over $10 \%$ of additional salt was measured in the biotite-bearing layer, with a slightly lower increase in the SB sample.

Mass balance analysis (Table 4) shows that no additional $\mathrm{NaCl}$ entered the samples; hence, pure redistribution of $\mathrm{NaCl}$ was observed in our experiments. The deviation of the mass calculated from binary data is for all three samples in the same order as the absolute error from image segmentation. 


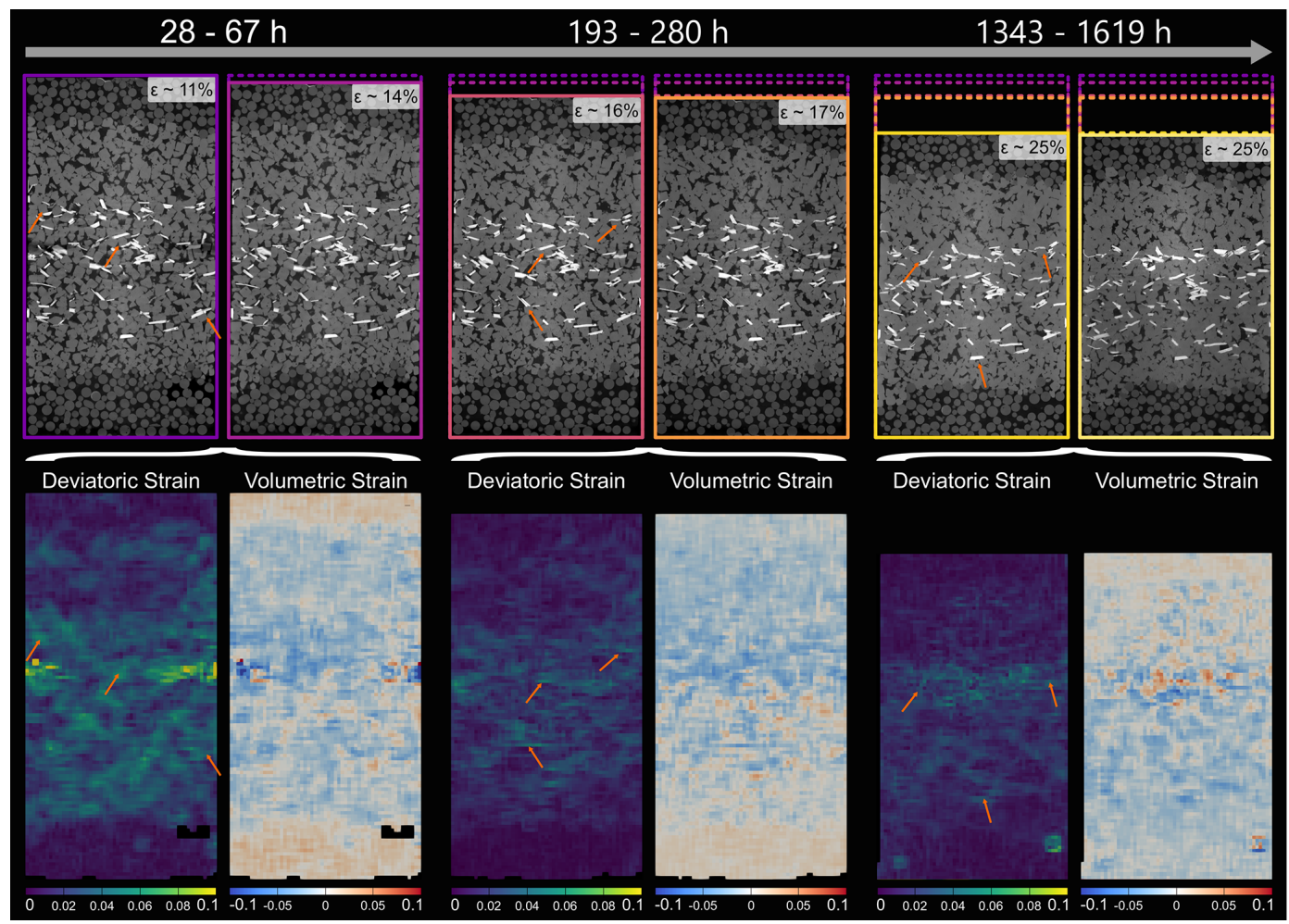

Figure 9. Locally resolved strain in the SBS sample. The absolute values of deviatoric and volumetric strain were calculated from digital volume correlation for three different time steps. The top row shows the two microtomography scans which were compared to each other using digital volume correlation. Further, the contours are showing the sample dimensions, ranging in colour from purple for the least compacted sample to light yellow for the most compacted sample. In the bottom row, the results of the strain calculation are displayed. Note that the strains are cumulative and cover the entire time interval between the two selected scans. The durations of the time intervals increase from the left to the right and are 39,87 and $276 \mathrm{~h}$. For the deviatoric strain, bright colours represent high strains, whereas dark colours represent low strains. For the volumetric strain, blue indicates compaction, while red indicates dilatation. Note that the strains are resolved on the grain scale. Arrows point to high deviatoric strains at $\mathrm{NaCl}-$ biotite interphase boundaries.

\section{Discussion}

\subsection{Length scales of $\mathrm{NaCl}$ transport during DPC - a qualitative exposition}

The experiments allowed us to compare bulk compaction of the sample to deformation on the grain scale in three different samples over a total duration of 1089 (pure $\mathrm{NaCl}$ ), 1619 (SBS) and $1932 \mathrm{~h}$ (SB). The general compaction behaviour we observed shows a qualitative similarity to previous studies on $\mathrm{NaCl}$ compaction (e.g. Spiers and Schutjens, 1990; Renard et al., 2004; Macente et al., 2018) except for the attainment of an apparent steady state. The exceptional length of our experiments allows further to qualitatively compare them to compaction data of salt used as backfill material, e.g. at the Waste Isolation Pilot Plant (WIPP) site. However, a direct comparison to published experimental compaction data is difficult as grain sizes and deformation conditions vary between individual studies. Therefore, we used the rate law by Spiers et al. (2004) to calculate strain rates of diffusion- controlled DPC with the parameters used in our experiments (Fig. 16).

At early stages our bulk strain rates are up to 1 order of magnitude higher than the calculated strain rates. However, with decreasing porosity, the measured strain rates progressively approach the calculated rates and broadly align with those. In the early stages of our experiments, elevated compaction rates could be the result of the formation of new effective dissolution sites by grain crushing and microfracturing. We acknowledge that locally plastic deformation may have occurred at small contacts where stress was concentrated; however, the effect upon the bulk deformation was negligible. One reason why DVC works in our experiments is that the centres of the $\mathrm{NaCl}$ grains did not deform; hence, deformation must have happened at the grain boundaries and not within the grains. DVC uses, within the limits of noise, the texture of the grains (expressed by the grey-scale distribution) to identify a labelled grain from the reference image in the deformed image. A grain deformed by crystal plastic deformation would show geometrical changes in its grey-scale distribution hence its texture. We would not expect DVC to 


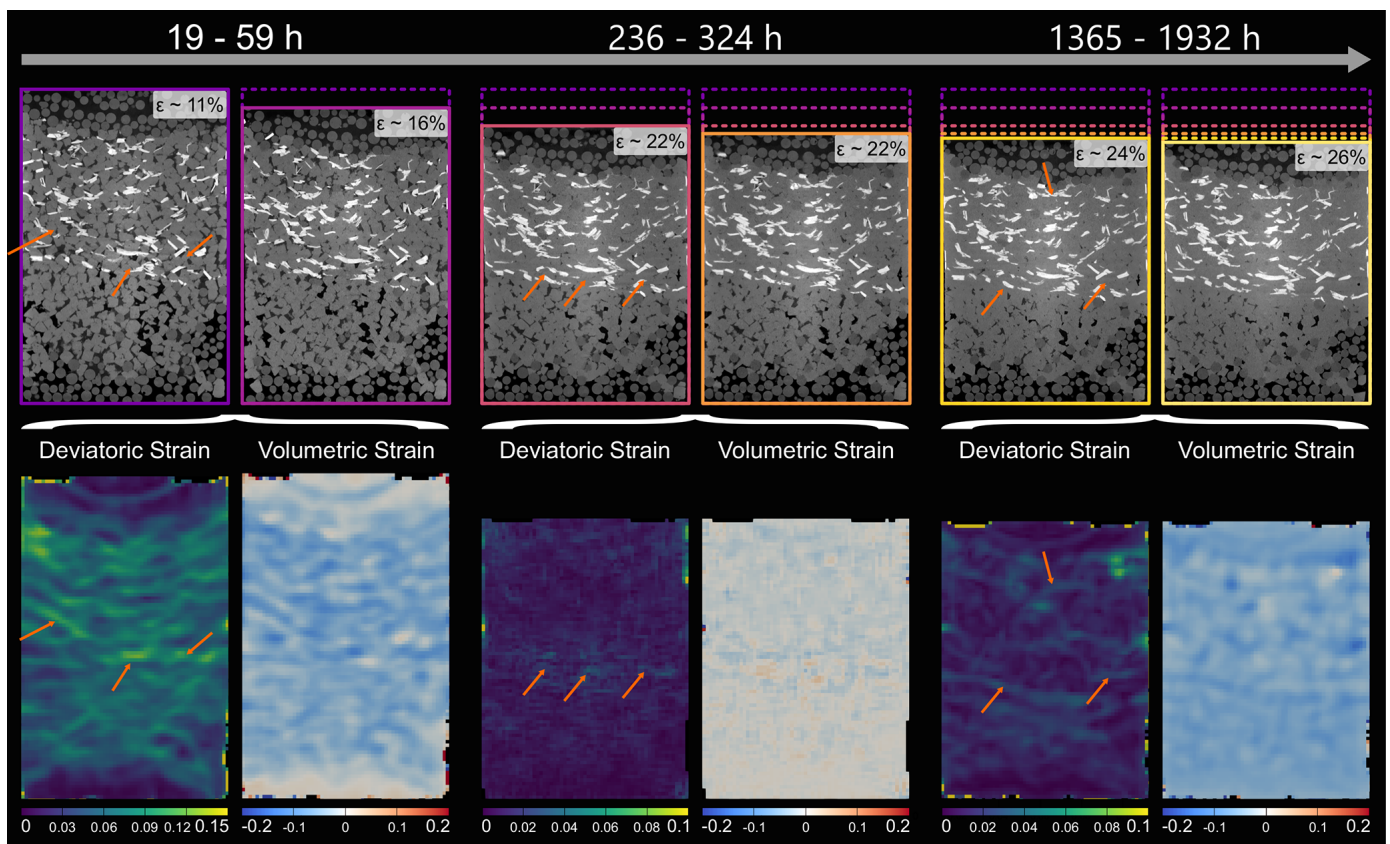

Figure 10. Locally resolved strain in the SB sample. The absolute values of deviatoric and volumetric strain were calculated from digital volume correlation for three different time steps. The top row shows the two microtomography scans which were compared to each other using digital volume correlation. Further, the contours are showing the sample dimensions, ranging in colour from purple for the least compacted sample to light yellow for the most compacted sample. In the bottom row, the results of the strain calculation are displayed. Note that the strains are cumulative and cover the entire time interval between the two selected scans. The time intervals increase from the left to the right and are 40, 88 and $567 \mathrm{~h}$. For the deviatoric strain, bright colours represent high strains, whereas dark colours represent low strains. For the volumetric strain, blue indicates compaction, while red indicates dilatation. Note the larger scale for the first time step of the deviatoric strain and that the strains are resolved on the grain scale. Arrows point to high deviatoric strains at NaCl-biotite interphase boundaries.

converge when the loss of mass and the change of grain texture occur simultaneously. We rather explain the differences between measured and calculated strain rates by a mechanical compaction component in the measured rates which is not included in the calculated rates.

Independent of the sample composition, the compaction was accomplished by an asymptotic decrease of the bulk strain rate. These observations indicate a change in the dominant deformation mode after $\sim 250 \mathrm{~h}$ of compaction. We interpret the non-linear character of our compaction and strain rate curves to display the transition from a state when mechanical compaction significantly contributes to the strain rate to an interlocked aggregate dominated by chemical compaction. Microstructural observations, which showed enhanced indentation of $\mathrm{NaCl}$ grains and reduction of pore space with progressing deformation (Fig. 6), point to the activity of dissolution-precipitation creep (e.g. Rutter, 1983; Tada and Siever, 1989; Gratier et al., 2013) during that period.

Visualisation of our results show that the compaction was accommodated across the entire biotite-bearing samples (Figs. 8-10), which is in conflict with models that postulate a pronounced effect of phyllosilicates on deformation localisa- tion (Heald, 1956; Thomson, 1959; Aharonov and Katsman, 2009) and acceleration of compaction (Hickman and Evans, 1995; Rutter and Wanten, 2000). We tested this observation by comparing the vertical displacement rates within the sample to the bulk compaction rate and by calculating locally resolved strains using digital image correlation. While we found that the biotite-bearing layers did not compact faster than the bulk samples, we also found that high deviatoric and volumetric strains were not restricted to the biotite-bearing layers. In fact, pure $\mathrm{NaCl}$ domains in biotite-bearing samples showed similar strain patterns (Figs. 9-11), and the overall strain distribution in these samples was comparable to the one observed in the pure $\mathrm{NaCl}$ reference sample. Therefore, we conclude that deformation was not localised in the biotitebearing layer but distributed and accommodated across all layers. Macente et al. (2018) came to a similar conclusion, explaining their results with a stress-bearing network of dynamic force chains in the pure $\mathrm{NaCl}$ domains which evolve in the granular material as response to a feedback of applied vertical loading and the increase in load-bearing crosssectional area due to local variations in the dissolution rate (Bruthans et al., 2014). Furthermore, they concluded that deformation was promoted by phase boundaries in the biotite- 


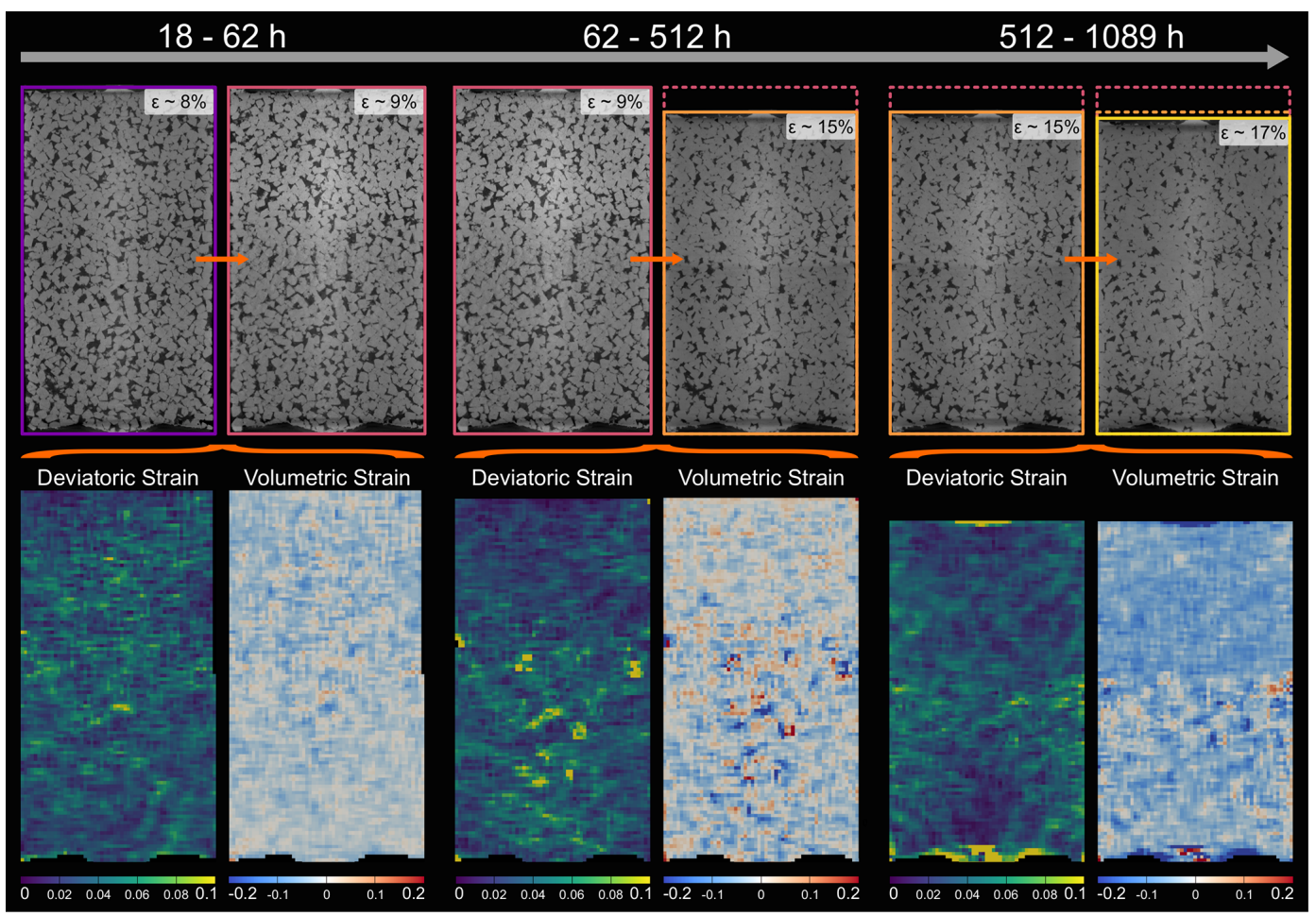

Figure 11. Locally resolved strain in the pure $\mathrm{NaCl}$ sample. The absolute values of deviatoric and volumetric strain were calculated from digital volume correlation for three different time steps. The top row shows the two microtomography scans which were compared to each other using digital volume correlation. Further, the contours are showing the sample dimensions, ranging in colour from purple for the least compacted sample to yellow for the most compacted sample. In the bottom row, the results of the strain calculation are displayed. Note that the strains are added up and cover the entire time interval between the two selected scans. The time intervals increase from the left to the right and are 44, 450 and $577 \mathrm{~h}$. For the deviatoric strain, bright colours represent high strains, whereas dark colours represent low strains. For the volumetric strain, blue indicates compaction, while red indicates dilatation.

bearing layer. Similar to Macente et al. (2018), we observed the highest porosity reduction in layers containing phyllosilicates. Compared to the pure $\mathrm{NaCl}$ layers, these layers lost $\sim 24 \%$ more in the SBS, and $\sim 41 \%$ more in the SB sample relative to the initial porosity in each layer. Combining the observations of higher porosity loss in the biotite-bearing layers with the evidence that compaction is not concentrated in those layers leads to a paradox that cannot be explained by the classical theory of DPC, which would suggest enhanced DPC to lead to strain localisation and thus a porosity loss. A possible solution would be diffusive material transport from a source outside the biotite-bearing layer into the pore space of that layer.

We were able to show that the $\mathrm{NaCl}$ content in the biotitebearing layers of the SB and SBS sample increased with progressing deformation (see Figs. 14 and 15), and we interpret this salt to have been sourced from the pure $\mathrm{NaCl}$ layers. In the SB sample the largest effect can be observed at the layer interface from which a negative gradient emerged towards the top of the biotite-bearing layer (Fig. 14b). In this case, the effect of the $\mathrm{NaCl}$ migration is restrained by the breakdown of porosity after $170 \mathrm{~h}$, which limits further migration of dissolved $\mathrm{NaCl}$ into the biotite-bearing layer from the suspected source in the pure $\mathrm{NaCl}$ layer at the bottom of the sample (Fig. 14b). In the SBS sample, we see no porosity breakdown and no gradient in the $\mathrm{NaCl}$ distribution emerge within the biotite-bearing layer. The porosity remains interconnected throughout the entire experiment, maintaining access to both $\mathrm{NaCl}$ layers as potential sources for salt. The biotite-bearing layer showed a consistently higher increase in $\mathrm{NaCl}$ than the marginal pure $\mathrm{NaCl}$ layers (Fig. 14a). The upper $\mathrm{NaCl}$ layer especially developed a pronounced gradient towards the interface with the biotite-bearing layer though, which could be evidence for a diffusive salt redistribution. Combined, we consider these observations strong evidence for $\mathrm{NaCl}$ diffusion over several hundred micrometres and multiple grain diameters into the biotite-bearing layer. For an unambiguous quantification of the length scales, further experiments are required which directly trace the dissolved material from source to sink using a tracer technique. However, these must be considered technically extremely challenging and beyond the scope of this study.

Potential driving forces for diffusive transport over extended length scales are gradients in temperature and en- 


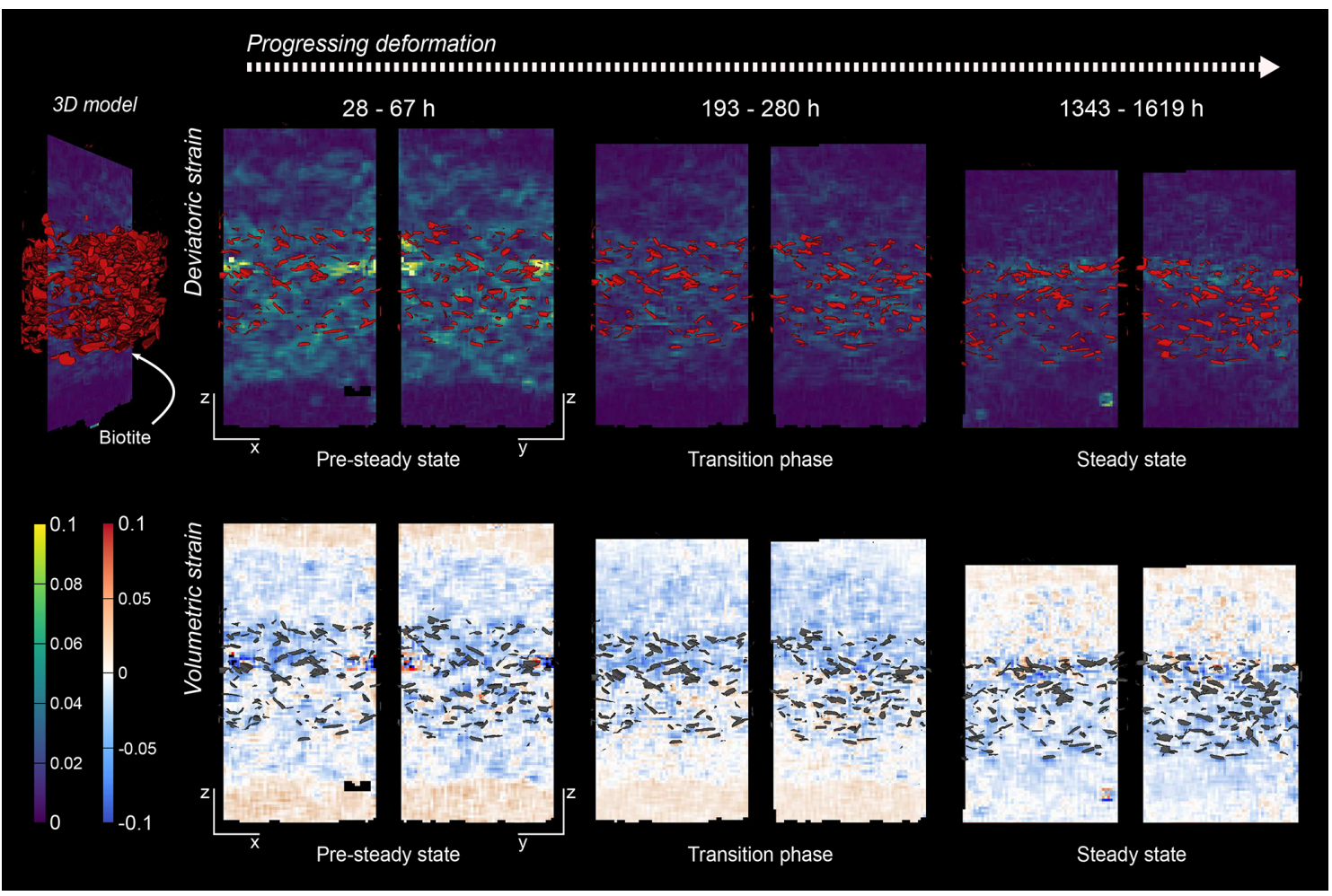

Figure 12. Comparison of the location of biotite grains with strain maxima derived from digital volume correlation in the SBS sample. The biotite was segmented from $\mu \mathrm{CT}$ scans and plotted on top of the corresponding vertical slice through the DVC result. The top row shows the deviatoric strain and the bottom row the volumetric strain of the SBS sample at three different stages of deformation. Note the different orientation of slices to display the three-dimensional information. With progressing deformation, the deviatoric strain is more focused in the biotite-bearing layer. However, maxima also occur in adjacent pure $\mathrm{NaCl}$ layers.

hanced solubility by irradiation damage within the samples and between layers of different composition. While we consider the former to be negligible in our samples, we are aware that irradiation damage may occur in our samples and influence the solubility of $\mathrm{NaCl}$. The $\mathrm{NaCl}$ which was recovered from the oedometer cells after deformation showed a change of colour from white to yellow, which points towards irradiation damage by the formation of $\mathrm{F}$ and $\mathrm{H}$ centres in the anion lattice of the crystal (e.g. Lidiard, 1998). However, as our bulk samples were all uniformly exposed to a similar dose, we consider lateral damage gradients within the samples to be negligible. Overall, we expect that the doses and irradiation periods in our experiments were too low to report an significant effect of irradiation damage upon the solution rate as even experiments conducted at Synchrotron sources did not observe an effect (e.g. Renard et al., 2004).

A model that could explain our observations of longdistance diffusive $\mathrm{NaCl}$ redistribution in the samples was proposed by Merino et al. (1983). They suggest that a locally increased porosity leads to reduced contact areas of grains and consequently higher local stresses along these contacts. In DPC, this causes an increased chemical potential and shift from an equilibrium between the fluid and the salt towards conditions that favour dissolution. Hence, the concentration of dissolved matter in the local pore fluid is increasing and diffusion occurs along a concentration gradient towards domains with a lower porosity, in our samples the biotite-bearing layers. There, due to lower local stresses at the grain contacts, the equilibrium concentration of the solute is reduced and precipitation in the open pore space occurs. This process is self-enforcing and reflects an instability of the system. The driving force of the mechanism is continuously maintained by the preferential precipitation in the biotite-bearing layer which progressively reduces the local stresses at grain contacts hence, the supersaturation of the pore fluid. For Merino's model to be applicable, the $\mathrm{NaCl}$ supersaturations produced by pressure solution must be maintained over transport distances greater than the grain scale before redeposition. Experiments by Desarnaud et al. (2014) demonstrate that, counterintuitively, large supersaturations of $\mathrm{NaCl}$ (up to $1.6 \times$ ) can persist in aqueous solutions before nucleation which explains, inter alia, the absent nucleation and precipitation of $\mathrm{NaCl}$ in the glass bead layers. Furthermore, Zimmermann et al. (2015) use atomistic simulations to demonstrate that the nucleation kinetics of $\mathrm{NaCl}$ are controlled by desolvation rather than diffusive transport. 
(a)

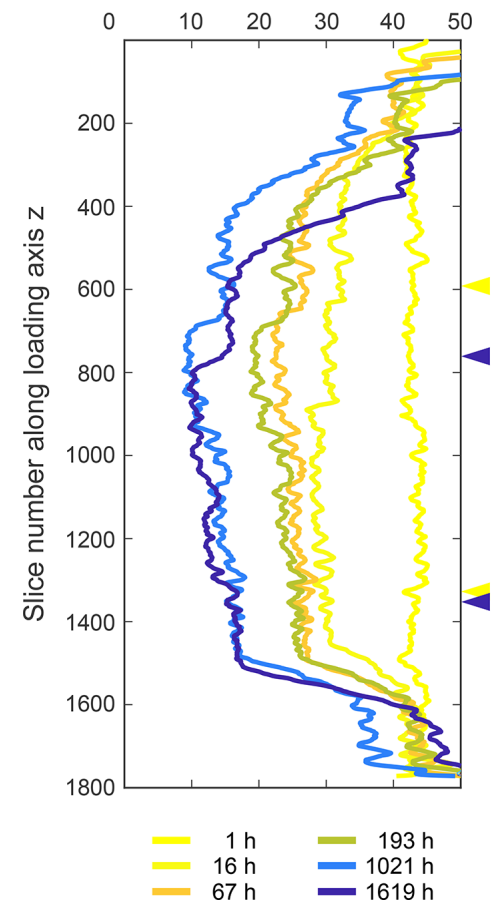

(b)

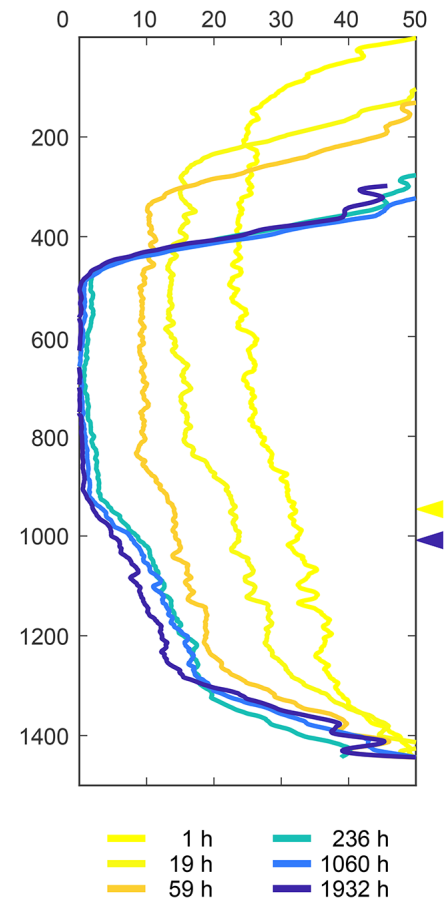

(c)

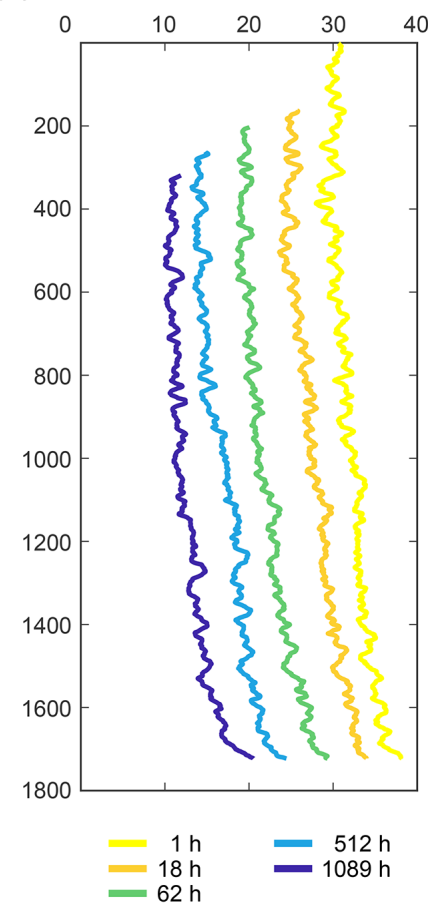

Figure 13. Porosity evolution of (a) the SBS (b) the SB sample and (c) the pure $\mathrm{NaCl}$ sample with progressing deformation. The porosity was measured as two-dimensional porosity for each slice along the loading axis. Different colours indicate different time steps, ranging from yellow to blue with progressing compaction. While heterogeneities arise in panels (a) and (b) which show the compositionally layered samples, panel (c) shows a homogeneous decrease of the porosity within the sample. The highest porosity loss occurs in biotite-bearing layers, resulting in the compartmentalisation of the SB sample (see Sect. 2.5). Note that the arrows on the right-hand side mark the transition from the pure $\mathrm{NaCl}$ domain to the $\mathrm{NaCl}$-biotite domain, and colours correspond to the deformation stage as denoted in the key.

We explain the initial porosity variation that is needed for Merino et al.'s feedback model with differences in shapes and sizes between the $\mathrm{NaCl}$ and biotite grains, where biotitebearing layers experienced greater packing density than the pure $\mathrm{NaCl}$ layers (Fig. 13), leading to lower initial porosity (Table 3). If the model applies to our results, this would in turn imply that driving forces for transport during DPC even in the absence of advective transport are more diverse than diffusion on the grain scale alone and thus more complex than classical models suggest (e.g. Raj, 1982; Rutter, 1983; Gratier, 1987).

This is in accordance with field observations by Heald (1956), Mimran (1977) and Buxton and Sibley (1981), who report observations that challenge the classical theory of precipitation in the vicinity of dissolution sites and invoke larger transport distances in sandstones, chalk and limestones, respectively.

\subsection{What is the role of the biotite?}

Our DVC analysis revealed that a proportion of the maxima in the grain-scale shear strains (see Figs. 9 and 10) corresponded to biotite- $\mathrm{NaCl}$ phase boundaries. Such phase boundaries are characterised by significant electrochemical effects (Walderhaug et al., 2006; Greene et al., 2009; Kristiansen et al., 2011), which may accelerate dissolution of $\mathrm{NaCl}$. Visualising such interfaces from our data showed the efficiency of this process (see Fig. 6). At the same time, our label analysis showed that biotite grains did not rotate significantly (Fig. 7). Especially during the early stages of compaction, where the sample still had a high porosity, we would expect point loading to force biotite grains to realign. We interpret the fact that this did not happen as corroborating evidence for the efficiency of dissolution at biotite- $\mathrm{NaCl}$ phase boundaries.

An increased efficiency of dissolution along phase boundaries would imply that the biotite-bearing layers should compact preferentially. This is an effect that we clearly did not observe in our data (see previous subsection and Figs. 8-10), which raises the question as to how the preferred dissolution is being balanced. We interpret this to happen in the following way: $\mathrm{NaCl}$ that is being dissolved at a biotite- $\mathrm{NaCl}$ phase boundary, or also along a $\mathrm{NaCl}$ grain boundary in the biotitebearing layer, is only redistributed locally, within that layer, so that the net volume of that layer is preserved. In the absence of advective transport in our experiment, this is in line with classical DPC theory (e.g. Paterson, 1973; Raj, 1982; Rutter, 1983; Gratier, 1987; Groshong Jr., 1988). This effect 
(a)

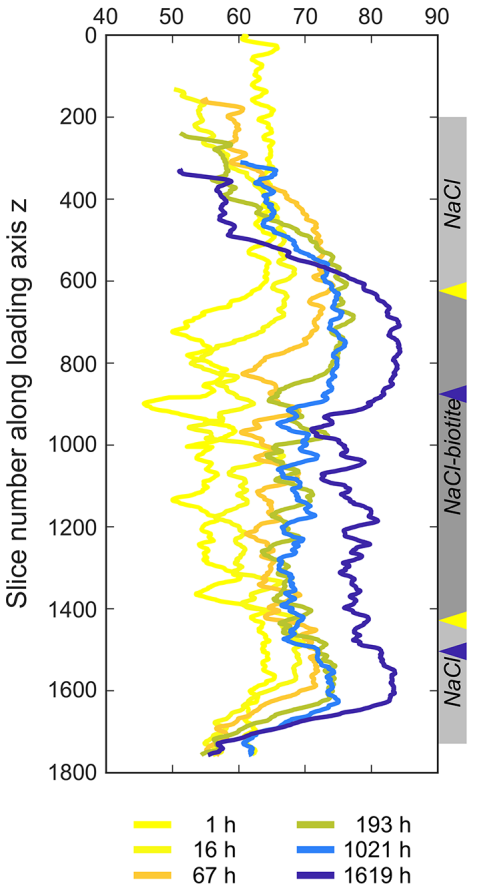

(b)

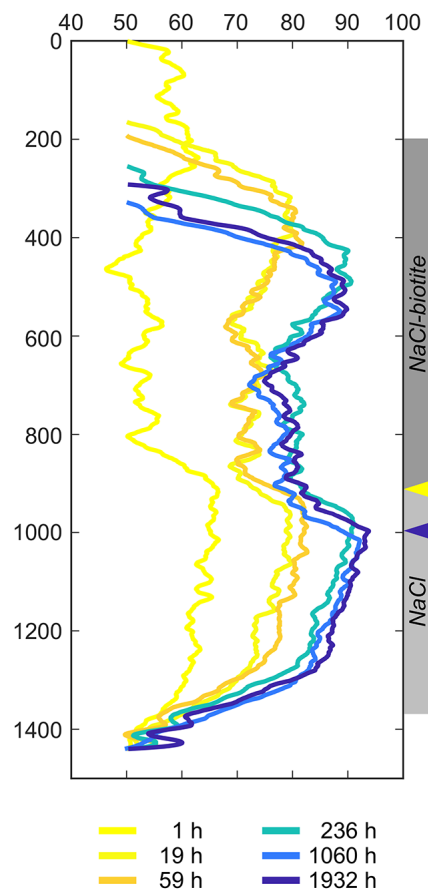

(c)
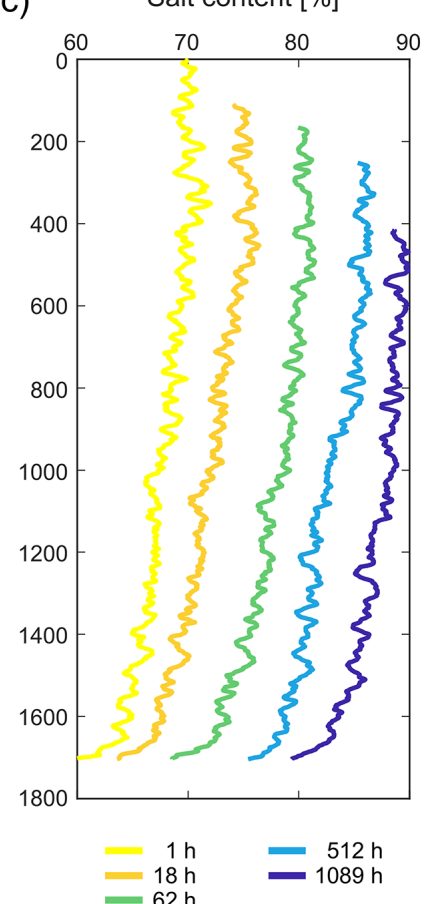

Figure 14. Evolving $\mathrm{NaCl}$ distribution in (a) the SBS, (b) the $\mathrm{SB}$ and (c) the pure $\mathrm{NaCl}$ sample with progressing deformation. The $\mathrm{NaCl}$ content was measured in 2-D for each slice along the loading axis. Panels (a) and (b) show that the $\mathrm{NaCl}$ content in the biotite-bearing layer increases more than in the rest of the sample, while panel (c) shows a homogeneous increase of the $\mathrm{NaCl}$ content within the sample. Note that the arrows on the side mark the position of the interface between the biotite-bearing layer and the pure $\mathrm{NaCl}$ layer, with their colours corresponding to the time steps as indicated in the key below. The grey bar reflects the sample composition at the initial compaction stage.

is supported by the diffusive potential described above and the additional $\mathrm{NaCl}$ that migrates into the layer (see previous subsection), whereby the additional $\mathrm{NaCl}$ contributes to a load-bearing framework whose compaction rate approximates the bulk sample's.

We do note that the biotite composition does not seem to have a first-order effect on pressure solution at its interfaces: while the biotite that Macente et al. (2017; 2018) used had a composition of $\quad \mathrm{K}_{0.9}\left(\mathrm{Mg}_{2.5} \mathrm{Fe}_{0.4} \mathrm{Al}_{0.1} \mathrm{Ti}_{0.1}\right)\left(\mathrm{Si}_{2.9} \mathrm{Al}_{1.1}\right) \mathrm{O}_{10}(\mathrm{OH})_{2}$, the one used in this study was richer in iron $\mathrm{K}_{0.7} \mathrm{Ca}_{0.1}\left(\mathrm{Fe}_{2.1} \mathrm{Mg}_{0.3} \mathrm{Ti}_{0.2}\right)\left(\mathrm{Si}_{2.5} \mathrm{Al}_{1.1}\right) \mathrm{O}_{10}(\mathrm{OH})_{2} \quad$ (see Table B2 in the Appendix for full compositions). Both cation sites are enclosed within the crystal structure of the biotite and are not exposed at the surface of the basal plane. As the latter is likely to be the reactive surface in the dissolution-precipitation creep mechanism, the observed differences in the chemical composition are not expected to affect the dissolution process.

In summary, while biotite grains locally are effective facilitators for DPC irrespective of their composition, it also appears that the chemo-mechanical effect on the entire system is limited and probably outperformed by the trans-domain diffusion outlined above.

\subsection{A detailed discussion of our DVC analyses}

\subsubsection{Magnitudes of local strains}

Our DVC analyses resolve deviatoric and volumetric strains on the grain scale (Figs. 9-12) and provide insights into the micromechanics of compaction in the various samples. Comparing the strains in the SBS with the SB sample showed the effect of the larger load that was used in the later compaction experiment; the maximum volumetric and deviatoric strains reached in the SB samples are about twice as high.

\subsubsection{Character of local strains and their location relative to phyllosilicates}

In all three samples, the dominating local volumetric strain was negative. This trend is persistent throughout the experiments and in line with the bulk deformation and vertical shortening of the samples. Deviations from this trend occurred at sites where porosity was reduced by precipitation of dissolved material. Combined, these strains reflect the deformation of the samples by active DPC, tracking the volume changes of the $\mathrm{NaCl}$ grains and porosity. The local positive maxima of the volumetric strain (in red) did not correlate with the location of biotite grains but with sites of precipitation (see Fig. 12). However, a pronounced concentration of 
(a) $\mathrm{NaCl}$-biotite- $\mathrm{NaCl}$ sample

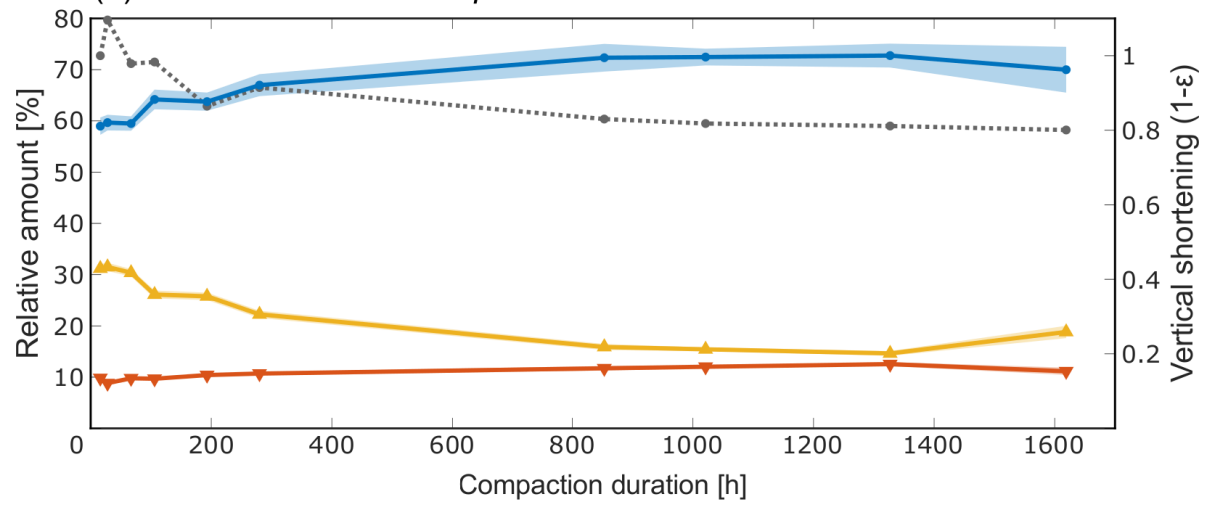

(b) NaCl-biotite sample

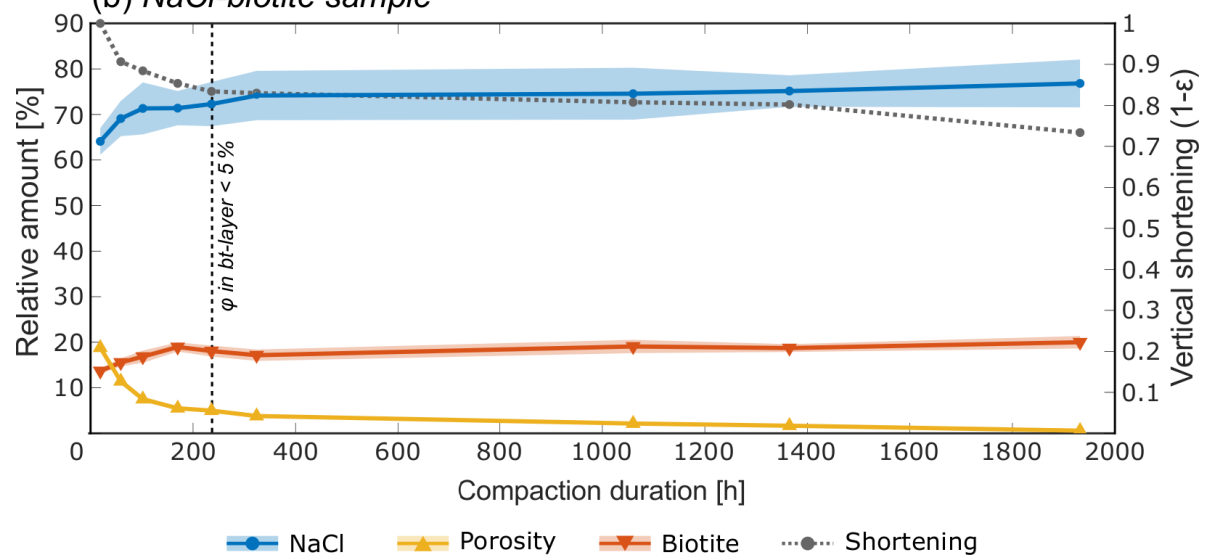

Figure 15. Evolution of the relative volumes of $\mathrm{NaCl}$, biotite and porosity in the biotite-bearing layers of (a) the SBS and (b) the SB sample, with progressing deformation. In both samples, the biotite content remains constant within the segmentation error (plotted as shade in the respective colour), while the $\mathrm{NaCl}$ content increases and the porosity decreases. This is persistent throughout the experiment. After $324 \mathrm{~h}$ of compaction, the increase of the $\mathrm{NaCl}$ content in the $\mathrm{SB}$ sample (b) stagnates, which corresponds to the breakdown of porosity in the biotite-bearing layer.

compaction as described in Macente et al. (2018) cannot be observed.

Deviatoric strain maxima on the other hand showed a certain correlation to the position of biotite grains but not exclusively. Elevated deviatoric strains were also found in the pure $\mathrm{NaCl}$ domains in proximity to the biotite-bearing layer which also show elevated strains. It could be argued that deviatoric strain maxima represent the mechanical sliding of grains past each other in an unconsolidated polycrystalline aggregate. However, the process causing the strain maxima continued during the apparent steady-state deformation. We rather relate these strain maxima to grain boundary sliding assisting and promoting dissolution and precipitation processes along grain boundaries independent of the sample composition.

\subsubsection{The use of DVC in changing samples}

In our analysis, we used continuum DVC to analyse samples that are changing, which violates a core assumption of image correlation, that of the preservation of mass. The fact that material gets dissolved and reprecipitated elsewhere should, in principle, cause problems with convergence of the algorithm. However, across all analysed data sets and increments, the analysis did correlate very well (animation S2 in the Supplement), with only negligible proportions of the volumes not correlating. This observation was persistent across all analysed data.

DVC is very sensitive to the choice of input parameters "half-window size" and "node spacing" which must be adapted to the underlying microstructure - here both of these parameters were carefully tuned to the grain size. Biotite is nonreactive on the scale of our observations and can thus be expected to correlate well. Interiors of $\mathrm{NaCl}$ grains are not changing during DPC, as dissolution and precipitation processes occur along the grain boundaries, while the grain centres are not affected by deformation. This means that the algorithm can confidently correlate volumes there. Further, during compaction, the relative proportion of grains versus pores was changing in favour of the former, which will inevitably render the correlation more robust. Lastly, the relative local changes in the texture in the investigated inter- 


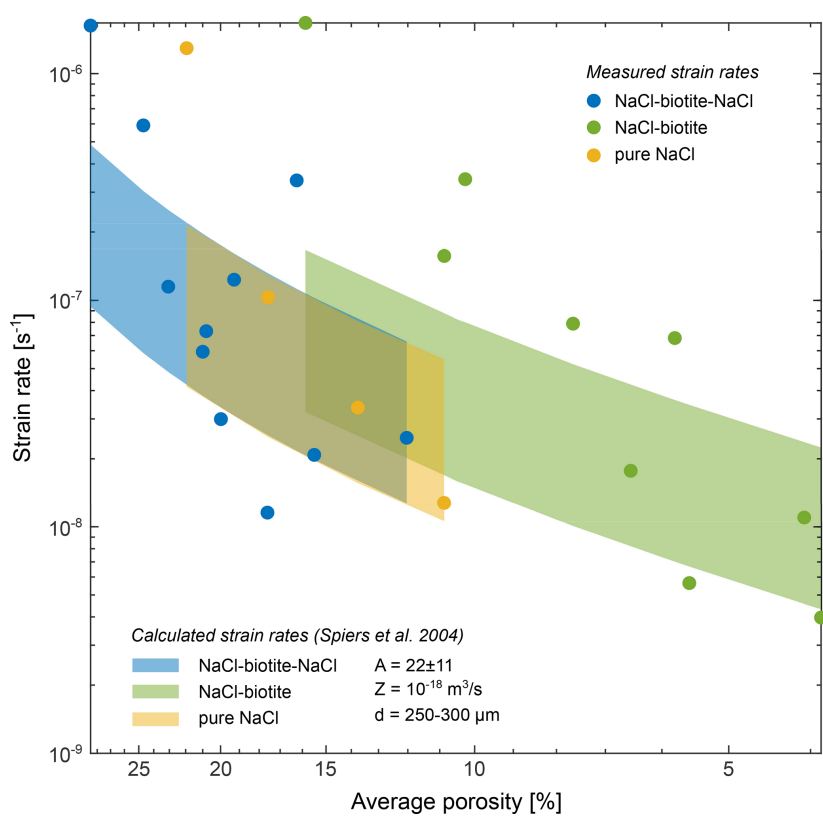

Figure 16. Comparison of bulk strain rates and calculated bulk strain rates based on the rate law by Spiers et al. (2004) for diffusion-controlled DPC: $\dot{\varepsilon}=A \frac{\mathrm{DCS}}{d^{3}} \frac{\sigma_{\mathrm{e}} \Omega^{\mathrm{S}}}{R T} f(\phi)$ with $\dot{\varepsilon}$ as the strain rate, $\mathrm{DCS}=Z$ a phenomenological coefficient which represents the effective grain boundary diffusivity, $d$ the grain size, $\sigma_{\mathrm{e}}$ the effective axial stress, $\Omega^{\mathrm{S}}$ the molar volume of the solid, $R$ the gas constant, $T$ the absolute temperature and $f(\phi)=2 \phi /(1-2 \phi)^{2}$ as a function of the porosity $(\phi)$. For the calculation, the parameters $A$ and $Z$ were used as given in Spiers et al. (1990) and Spiers et al. (2004), respectively. The maximum strain rate was calculated for a geometrical constant $A=33$ (6-fold coordination) and a grain size of $d=250 \mu \mathrm{m}$. The minimum strain rate was similarly calculated for $A=11$ (12-fold coordination) and $d=300 \mu \mathrm{m}$. Our measured data broadly align with the calculated strain rates at the same porosity.

vals were moderate. Although mass was lost along the grain boundaries, the main body of the particles remains constant over the increment. We consider the combination of these parameters responsible for the successful correlation in our DVC analyses and thus conclude that the application of the technique in our samples is possible.
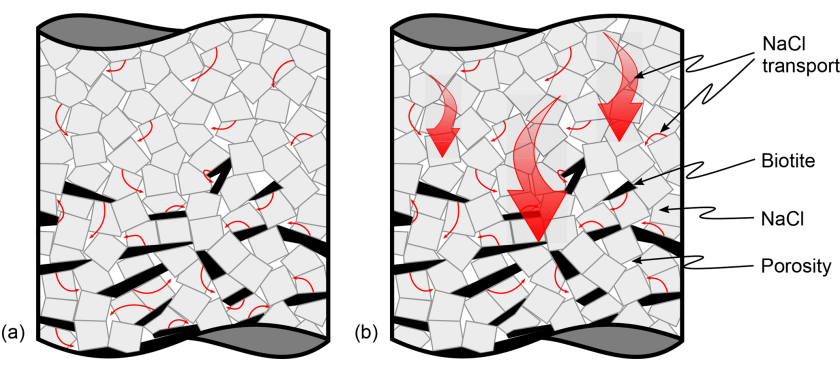

Figure 17. Possible transport length scales during dissolutionprecipitation creep as proposed within the scope of this work. In panel (a), diffusion occurs only on the grain scale as described in the classical literature. In panel (b), we added diffusive transport on longer length scales as described in Merino et al. (1983). However, diffusive transport on the grain scale is considered to be active as well.

\section{Conclusions}

In this study, we have investigated active dissolutionprecipitation creep in closed $\mathrm{NaCl}$-biotite systems and its contribution to the dynamic evolution of hydraulic rock properties during diagenesis. Our findings indicate that the presence of phyllosilicates enhances porosity reduction but has no obvious effect on deformation localisation, as compaction is accommodated in all layers and local strain maxima are homogeneously distributed within the samples. Following Merino et al. (1983), we explain this paradox with diffusive material migration exceeding the grain scale, from sources in the marginal pure $\mathrm{NaCl}$ layer to sinks in the central biotitebearing layer. This invites a renewed discussion on the influence of phyllosilicates and the driving forces for material transport during dissolution-precipitation creep with direct implications to the diagenetic compartmentalisation of rocks and stylolite formation. 
Appendix A: Additional information on the methodology

\section{A1 Experimental conditions for oedometric compaction experiments}

Table A1. Experimental conditions for oedometric compaction experiments.

\begin{tabular}{lrrrrr}
\hline Sample type & $\begin{array}{l}\text { Axial load on } \\
\text { actuator [MPa] }\end{array}$ & $\begin{array}{l}\text { Axial load on } \\
\text { sample [MPa }]\end{array}$ & $\begin{array}{l}\text { Fluid pressure } \\
{[\mathrm{MPa}]}\end{array}$ & $\begin{array}{l}\text { Effective stress } \\
{[\mathrm{MPa}]}\end{array}$ & $\begin{array}{l}\text { Average temperature } \\
{\left[{ }^{\circ} \mathrm{C}\right]}\end{array}$ \\
\hline Pure $\mathrm{NaCl}$ & 0.43 & 6.84 & 0.2 & 6.64 & 22.3 \\
$\mathrm{NaCl}-$ biotite & 0.43 & 10.74 & 0.2 & 10.54 & 21.1 \\
$\mathrm{NaCl}-$ biotite- $\mathrm{NaCl}$ & 0.45 & 7.27 & 0.5 & 6.77 & 21.9 \\
\hline
\end{tabular}

\section{A2 Acquisition parameter for X-ray microtomography} scans

Table A2. Acquisition parameter for X-ray microtomography scans.

\begin{tabular}{lll|ll}
\hline Scan parameters & \multicolumn{2}{c}{ SBS } & SB & S \\
\cline { 2 - 4 } & Scans 1 to 8 & Scans 9 to 19 & Scans 1 to 10 & Scans 1 to 5 \\
\hline Acceleration voltage & $100 \mathrm{kV}$ & & $120 \mathrm{kV}$ & $120 \mathrm{kV}$ \\
Target power & $2.8 \mathrm{~W}$ & & $2.8 \mathrm{~W}$ & $2.8 \mathrm{~W}$ \\
No. of projections & 2000 & & 2000 & 2000 \\
Exposure time & $2 \mathrm{~s}$ & & $2 \mathrm{~s}$ & $2 \mathrm{~s}$ \\
Source-to-sample distance & $19.5 \mathrm{~mm}$ & $18.25 \mathrm{~mm}$ & $19.25 \mathrm{~mm}$ & $19.25 \mathrm{~mm}$ \\
Source-to-camera distance & $705.75 \mathrm{~mm}$ & $706.25 \mathrm{~mm}$ & $712.8 \mathrm{~mm}$ & $712.8 \mathrm{~mm}$ \\
Duration of scan & $67 \mathrm{~min}$ & & $67 \mathrm{~min}$ & $67 \mathrm{~min}$ \\
Filter & $0.3 \mathrm{~mm} \mathrm{Al} \mathrm{filter}$ & & $0.3 \mathrm{~mm} \mathrm{Al} \mathrm{filter}$ & $0.3 \mathrm{~mm} \mathrm{Al} \mathrm{filter}$ \\
10 dark current and 10 flat field images & yes & & yes & yes \\
\hline Voxel size & $0.005469 \mathrm{~mm}$ & $0.005115 \mathrm{~mm}$ & $0.005346 \mathrm{~mm}$ & $0.005346 \mathrm{~mm}$ \\
\hline
\end{tabular}




\section{A3 Location of subvolumes for $\mathrm{NaCl}$ measurements}

\section{A4 Lambert projection}

The Lambert projection is an equal area projection similar to the Schmidt net used in geology. In contrast to the Schmidt net, the Lambert projection is a hemispherical polar projection with the pole of the sphere in its centre, while the Schmidt net is a spherical equatorial projection. They are read in a similar fashion. Note that the projections (Lambert and Schmidt) are perpendicular to each other. The interested reader may be referred to Snyder (1987). We used Lambert projections as they are a good statistical tool to analyse directional data.

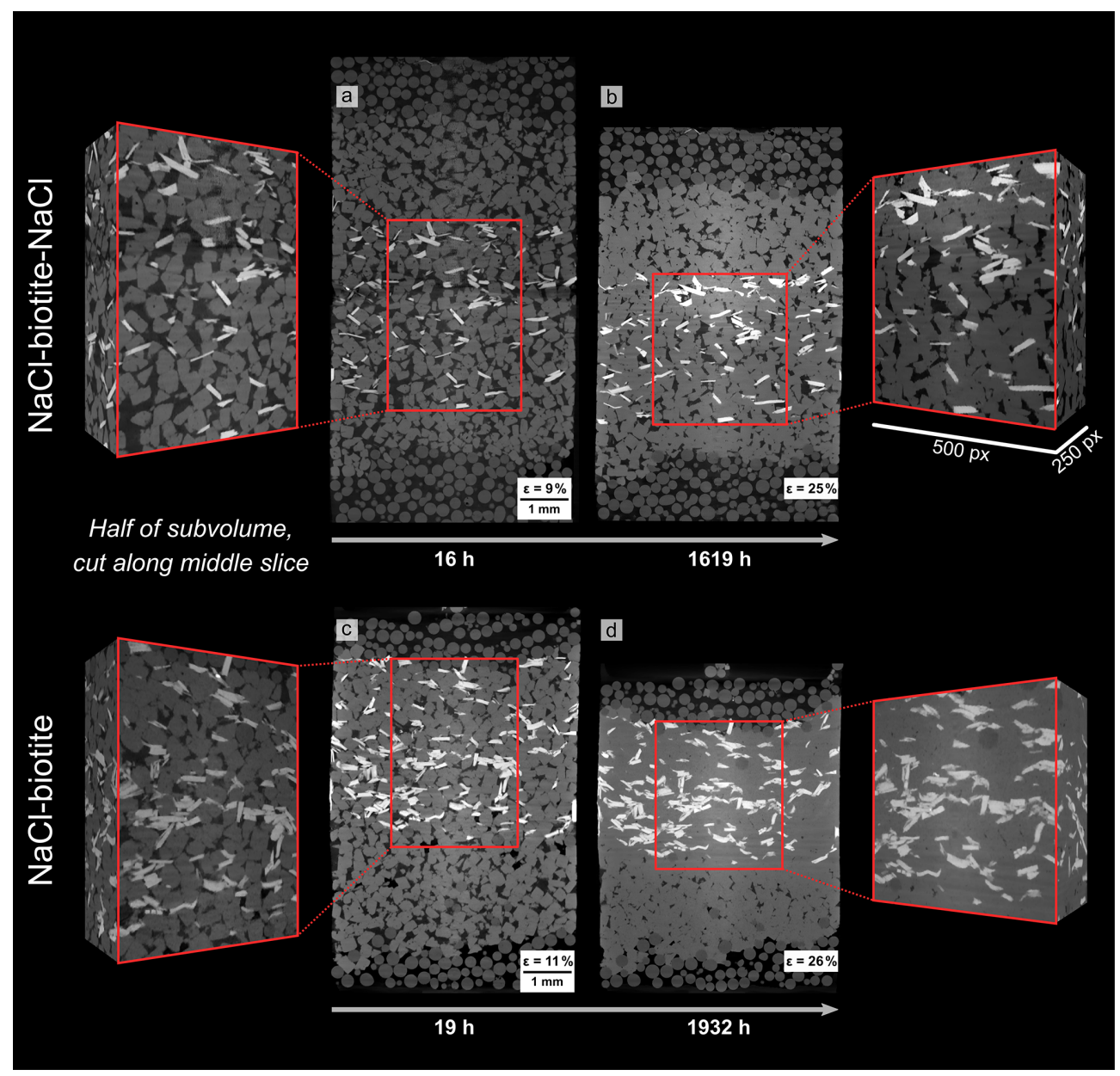

Figure A1. Location of the subvolumes used for the volumetric $\mathrm{NaCl}$ measurements relative to the sample. The top row shows the location of the subvolume at the beginning and the end of the experiment within the SBS sample while the bottom row shows it for the SB sample. The subvolumes are centred around a vertical slice that runs through the middle of the sample. Hence, the depicted subvolumes represent only half of the volume used for the measurement. 


\section{Appendix B: Additional information on the results}

\section{B1 Minimum deviatoric strain from DVC measurement}

Table B1. Minimum deviatoric strain as displayed in Figs. 11, 10 and 9 .

\begin{tabular}{lrrr}
\hline Correlation pair & SB & SBS & S \\
\hline 1 & 0.00129 & $6.793 \times 10^{-9}$ & 0.00523 \\
2 & 0.00774 & $8.908 \times 10^{-10}$ & 0.00585 \\
3 & 0.00494 & $1.499 \times 10^{-9}$ & 0.00441 \\
\hline
\end{tabular}

\section{B2 XRF analysis of biotite}

Table B2. X-ray fluorescence (XRF) analysis of mica used in our experiments (Bt-BS) and in Macente et al. (2018) (Mc-AM). Values are given in $\mathrm{wt} \%$.

\begin{tabular}{lrr}
\hline Sample & Bt-BS & Mc-AM \\
\hline $\mathrm{SiO}_{2}$ & 35.29 & 42.52 \\
$\mathrm{TiO}_{2}$ & 2.941 & 0.90 \\
$\mathrm{Al}_{2} \mathrm{O}_{3}$ & 12.60 & 14.30 \\
$\mathrm{Fe}_{2} \mathrm{O}_{3}$ & 35.68 & 6.28 \\
$\mathrm{MnO}$ & 0.381 & 0.06 \\
$\mathrm{MgO}$ & 2.99 & 24.19 \\
$\mathrm{CaO}$ & 1.32 & 0 \\
$\mathrm{Na} 2 \mathrm{O}$ & 0.07 & 0 \\
$\mathrm{~K}_{2} \mathrm{O}$ & 7.647 & 10.39 \\
$\mathrm{P} 2 \mathrm{O}_{5}$ & 0.091 & 0.01 \\
\hline LOI & 0.81 & 0.77 \\
\hline Total & 99.83 & 99.42 \\
\hline
\end{tabular}

Data availability. The data that support the findings of this study are available from the corresponding author, BS, upon reasonable request.

Supplement. The supplement related to this article is available online at: https://doi.org/10.5194/se-13-41-2022-supplement.

Author contributions. BS, FF and IBB designed the study. BS ran the experiments. EA supplied the digital volume correlation code and helped with the analysis. All authors were involved in the interpretation of the results and the writing of the final manuscript.

Competing interests. At least one of the (co-)authors is a member of the editorial board of Solid Earth. The peer-review process was guided by an independent editor, and the authors also have no other competing interests to declare.

Disclaimer. Publisher's note: Copernicus Publications remains neutral with regard to jurisdictional claims in published maps and institutional affiliations.

Acknowledgements. We would like to thank Johannes Glodny from GFZ for the provision of sieved biotite mineral separates. Alex Hart and Ivan Febbrari are thanked for technical support. We also kindly thank the two anonymous reviewers for their helpful reviews.

Financial support. This work was financially supported be the School of Geosciences, The University of Edinburgh.

Review statement. This paper was edited by David Healy and reviewed by two anonymous referees.

\section{References}

Aharonov, E. and Katsman, R.: Interaction between pressure solution and clays in stylolite development: Insights from modeling, Am. J. Sci., 309, 607-632, https://doi.org/10.2475/07.2009.04, 2009.

Arganda-Carreras, I., Kaynig, V., Rueden, C., Eliceiri, K. W., Schindelin, J., Cardona, A., and Sebastian Seung, H.: Trainable Weka Segmentation: a machine learning tool for microscopy pixel classification, Bioinformatics, 33, 2424-2426, https://doi.org/10.1093/bioinformatics/btx180, 2017.

Bons, P. D. and Urai, J. L.: Experimental deformation of twophase rock analogues, Mat. Sci. Eng. A, 175, 221-229, https://doi.org/10.1016/0921-5093(94)91061-8, 1994.

Bruthans, J., Soukup, J., Vaculikova, J., Filippi, M., Schweigstillova, J., Mayo, A. L., Masin, D., Kletetschka, G., and Rihosek, J.: Sandstone landforms shaped by negative feedback between stress and erosion, Nat. Geosci., 7, 597-601, https://doi.org/10.1038/ngeo2209, 2014.

Buades, A., Coll, B., and Morel, J.-M.: Non-local means denoising, Image Processing On Line, 1, 208-212, https://doi.org/10.5201/ipol.2011.bcm_nlm, 2011.

Buxton, T. M. and Sibley, D. F.: Pressure solution features in a shallow buried limestone, J. Sediment. Res., 51, 19-26, https://doi.org/10.1306/212F7BF8-2B24-11D78648000102C1865D, 1981.

Carter, N. L. and Hansen, F. D.: Creep of rocksalt, Tectonophysics, 92, 275-333, https://doi.org/10.1016/0040-1951(83)90200-7, 1983.

Coble, R.: A model for boundary diffusion controlled creep in polycrystalline materials, Int. J. Appl. Phys., 34, 1679-1682, https://doi.org/10.1063/1.1702656, 1963.

Croize, D., Renard, F., and Gratier, J.-P.: Compaction and porosity reduction in carbonates: A review of observations, theory, and experiments, in: Advances in Geophysics, vol. 54, pp. 181- 
238, https://doi.org/10.1016/B978-0-12-380940-7.00003-2, Elsevier, Amsterdam, Netherlands, 2013.

Desarnaud, J., Derluyn, H., Carmeliet, J., Bonn, D., and Shahidzadeh, N.: Metastability Limit for the Nucleation of $\mathrm{NaCl}$ Crystals in Confinement, J. Phys. Chem. Lett., 5, 890-895, https://doi.org/10.1021/jz500090x, 2014.

Dierick, M., Masschaele, B., and Van Hoorebeke, L.: Octopus, a fast and user-friendly tomographic reconstruction package developed in LabView®, Measurement Science and Technology, 15, 1366, https://doi.org/10.1088/0957-0233/15/7/020, 2004.

Durney, D.: Solution-transfer, an important geological deformation mechanism, Nature, 235, 315, https://doi.org/10.1038/235315a0, 1972.

Durney, D.: A Discussion on natural strain and geological structurePressure-solution and crystallization deformation, Philos. T. R. Soc. A, 283, 229-240, https://doi.org/10.1098/rsta.1976.0081, 1976.

Gratier, J.: Pressure solution-deposition creep and associated tectonic differentiation in sedimentary rocks, Geol. Soc. Spec. Publ., 29, 25-38, https://doi.org/10.1144/GSL.SP.1987.029.01.03, 1987.

Gratier, J.-P., Dysthe, D. K., and Renard, F.: The role of pressure solution creep in the ductility of the Earth's upper crust, in: Advances in Geophysics, vol. 54, pp. 47-179, https://doi.org/10.1016/B978-0-12-380940-7.00002-0, Elsevier, Amsterdam, Netherlands, 2013.

Green, H.: "Pressure solution" creep: some causes and mechanisms, J. Geophys. Res.-Sol. Ea., 89, 4313-4318, https://doi.org/10.1029/JB089iB06p04313, 1984.

Greene, G. W., Kristiansen, K., Meyer, E. E., Boles, J. R., and Israelachvili, J. N.: Role of electrochemical reactions in pressure solution, Geochim. Cosmochim. Ac., 73, 2862-2874, https://doi.org/10.1016/j.gca.2009.02.012, 2009.

Groshong Jr., R. H.: Low-temperature deformation mechanisms and their interpretation, Geol. Soc. Am. Bull., 100, 1329-1360, https://doi.org/10.1130/00167606(1988)100<1329:LTDMAT>2.3.CO;2, 1988.

Gundersen, E., Renard, F., Dysthe, D. K., Bjørlykke, K., and Jamtveit, B.: Coupling between pressure solution creep and diffusive mass transport in porous rocks, J. Geophys. Res.-Sol. Ea., 107, ECV-19, https://doi.org/10.1029/2001JB000287, 2002.

Hansen, F. D. and Leigh, C. D.: Salt disposal of heat-generating nuclear waste, Sandia National Laboratories Albuquerque, NM, https://doi.org/10.2172/1005078, United States, 2011.

Heald, M. T.: Cementation of Simpson and St. Peter sandstones in parts of Oklahoma, Arkansas, and Missouri, J. Geol., 64, 16-30, https://doi.org/10.1086/626314, 1956.

Herring, C.: Diffusional viscosity of a polycrystalline solid, Int. J. Appl. Phys., 21, 437-445, https://doi.org/10.1063/1.1699681, 1950.

Hickman, S. H. and Evans, B.: Kinetics of pressure solution at halite-silica interfaces and intergranular clay films, J. Geophys. Res.-Sol. Ea., 100, 13113-13132, https://doi.org/10.1029/95JB00911, 1995.

Kristiansen, K., Valtiner, M., Greene, G. W., Boles, J. R., and Israelachvili, J. N.: Pressure solution-The importance of the electrochemical surface potentials, Geochim. Cosmochim. Ac., 75, 6882-6892, https://doi.org/10.1016/j.gca.2011.09.019, 2011.
Lehner, F. K.: A model for intergranular pressure solution in open systems, Tectonophysics, 245, 153-170, https://doi.org/10.1016/0040-1951(94)00232-X, 1995.

Lidiard, A.: The Radiolysis of Alkali Halides - the Nucleation and Growth of Aggregates, Z. Phys. Chem., 206, 219-248, 1998.

Macente, A.: 4-dimensional studies of fluid-rock interactions, $\mathrm{PhD}$ thesis, School of Geosciences, University of Edinburgh, Edinburgh, UK, 2017.

Macente, A., Fusseis, F., Butler, I. B., Tudisco, E., Hall, S. A., and Andò, E.: 4D porosity evolution during pressure-solution of $\mathrm{NaCl}$ in the presence of phyllosilicates, Earth Planet. Sc. Lett., 502, 115-125, https://doi.org/10.1016/j.epsl.2018.08.032, 2018.

McClay, K.: Pressure solution and Coble creep in rocks and minerals: a review, J. Geol. Soc. London, 134, 57-70, https://doi.org/10.1144/gsjgs.134.1.0057, 1977.

Merino, E., Ortoleva, P., and Strickholm, P.: Generation of evenly-spaced pressure-solution seams during (late) diagenesis: A kinetic theory, Contrib. Mineral. Petr., 82, 360-370, https://doi.org/10.1007/BF00399713, 1983.

Mimran, Y.: Chalk deformation and large-scale migration of calcium carbonate, Sedimentology, 24, 333-360, https://doi.org/10.1111/j.1365-3091.1977.tb00127.x, 1977.

Object Research Systems (ORS) Inc.: Dragonfly, available at: http: //www.theobjects.com/dragonfly (last access: 1 June 2021), Object Research Systems (ORS) Inc, Montreal, Canada, 2021.

Paterson, M.: Nonhydrostatic thermodynamics and its geologic applications, Rev. Geophys., 11, 355-389, https://doi.org/10.1029/RG011i002p00355, 1973.

Peach, C.: Influence of deformation on the fluid transport properties of salt rocks, $\mathrm{PhD}$ thesis, Faculteit Aardwetenschappen der Rijksuniversiteit te Utrecht, Utrecht, Netherlands, 1991.

Peng, T., Thorn, K., Schroeder, T., Wang, L., Theis, F. J., Marr, C., and Navab, N.: A BaSiC tool for background and shading correction of optical microscopy images, Nat. Commun., 8, 14836, https://doi.org/10.1038/ncomms14836, 2017.

Raj, R.: Creep in polycrystalline aggregates by matter transport through a liquid phase, J. Geophys. Res.-Sol. Ea., 87, 47314739, https://doi.org/10.1029/JB087iB06p04731, 1982.

Renard, F., Dysthe, D., Feder, J., Bjørlykke, K., and Jamtveit, B.: Enhanced pressure solution creep rates induced by clay particles: Experimental evidence in salt aggregates, Geophys. Res. Lett., 28, 1295-1298, https://doi.org/10.1029/2000GL012394, 2001.

Renard, F., Bernard, D., Thibault, X., and Boller, E.: Synchrotron 3D microtomography of halite aggregates during experimental pressure solution creep and evolution of the permeability, Geophys. Res. Lett., 31, L07607, https://doi.org/10.1029/2004GL019605, 2004.

Rutter, E.: Pressure solution in nature, theory and experiment, J. Geol. Soc. London, 140, 725-740, https://doi.org/10.1144/gsjgs.140.5.0725, 1983.

Rutter, E. and Wanten, P.: Experimental study of the compaction of phyllosilicate-bearing sand at elevated temperature and with controlled pore water pressure, J. Sediment. Res., 70, 107-116, https://doi.org/10.1306/2DC40902-0E4711D7-8643000102C1865D, 2000.

Schindelin, J., Arganda-Carreras, I., Frise, E., Kaynig, V., Longair, M., Pietzsch, T., Preibisch, S., Rueden, C., Saalfeld, S., Schmid, B., Tinevez, J.-Y., White, D. J., Hartenstein, V., Eliceiri, K., Tomancak, P., and Cardona, A.: Fiji: an open-source 
platform for biological-image analysis, Nat. Methods, 9, 676, https://doi.org/10.1038/nmeth.2019, 2012.

Schutjens, P. and Spiers, C. J.: Intergranular Pressure Solution in Nacl: Grain-To-Grain Contact Experiments under the Optical Microscope, in: Dossier: Euroconference on Pore Pressure, Scale Effect and the Deformation of Rocks, 16-20 November 1998, Aussois, France, vol. 54, Oil \& Gas Science and Technology Rev. IFP, https://doi.org/10.2516/ogst:1999062, 1999.

Snyder, J. P.: Map projections-A working manual, vol. 1395, US Government Printing Office, Washington, D.C., https://doi.org/10.3133/pp1395, 1987.

Spiers, C., Schutjens, P., Brzesowsky, R., Peach, C., Liezenberg, J., and Zwart, H.: Experimental determination of constitutive parameters governing creep of rocksalt by pressure solution, Geological Society, London, Special Publications, 54, 215-227, https://doi.org/10.1144/GSL.SP.1990.054.01.21, 1990.

Spiers, C., De Meer, S., Niemeijer, A., and Zhang, X.: Kinetics of rock deformation by pressure solution and the role of thin aqueous films, Front. Sci. Series, in: Physicochemistry of Water in Geological and Biological Systems - Structures and Properties of Thin Aqueous Films, edited by: Nakashima, S., Spiers, C. J., Mercury, L., Fenter, P. A., and Hochella Jr., M. F., Universal Academy Press, Tokyo, 129-158, 2004.

Spiers, C. J. and Schutjens, P. M.: Densification of crystalline aggregates by fluid-phase diffusional creep, in: Deformation processes in minerals, ceramics and rocks, vol. 1, pp. 334-353, https://doi.org/10.1007/978-94-011-6827-4_13, Springer, Dordrecht, 1990.

Stamati, O., Andò, E., Roubin, E., Cailletaud, R., Wiebicke, M., Pinzon, G., Couture, C., Hurley, R. C., Caulk, R., Caillerie, D., Matsushima, T., Bésuelle, P., Bertoni, F., Arnaud, T., Ortega Laborin, A., Rorato, R., Sun, Y., Tengattini, A., Okubadejo, O., Colliat, J.-B., Saadatfar, M., Garcia, F. E., Papazoglou, C., Vego, I., Brisard, S., Dijkstra, J., and Birmpilis, G.: spam: Software for Practical Analysis of Materials, J. Open Source Softw., 5, 2286, https://doi.org/10.21105/joss.02286, 2020.
Tada, R. and Siever, R.: Pressure solution during diagenesis, Annu. Rev. Earth Pl. Sc., 17, 89-118, https://doi.org/10.1146/annurev.ea.17.050189.000513, 1989.

Thomson, A.: Pressure Solution and Porosity, in: Silica in Sediments, vol. 7, https://doi.org/10.2110/pec.59.01.0092, SEPM Society for Sedimentary Geology, Tulsa, Oklahoma, USA, 1959.

Trurnit, P.: Pressure solution phenomena in detrital rocks, Sediment. Geol., 2, 89-114, https://doi.org/10.1016/0037-0738(68)900304, 1968.

Tudisco, E., Andò, E., Cailletaud, R., and Hall, S. A.: TomoWarp2: A local digital volume correlation code, SoftwareX, 6, 267-270, https://doi.org/10.1016/j.softx.2017.10.002, 2017.

Urai, J., Schléder, Z., Spiers, C., and Kukla, P.: Flow and transport properties of salt rocks, in: Dynamics of complex intracontinental basins: The central European basin system, edited by: Littke, R., Bayer, U., Gajewski, D., and Nelskamp, S., Springer Berlin, https://doi.org/10.1007/978-3-540-85085-4, pp. 277-290, 2008.

von Berlepsch, T. and Haverkamp, B.: Salt as a Host Rock for the Geological Repository for Nuclear Waste, Elements, 12, 257262, https://doi.org/10.2113/gselements.12.4.257, 2016.

Walderhaug, O., Bjørkum, P. A., and Aase, N. E.: Kaolin-coating of stylolites, effect on quartz cementation and general implications for dissolution at mineral interfaces, J. Sediment. Res., 76, 234 243, https://doi.org/10.2110/jsr.2006.015, 2006.

Weyl, P. K.: Pressure solution and the force of crystallization: a phenomenological theory, J. Geophys. Res., 64, 2001-2025, https://doi.org/10.1029/JZ064i011p02001, 1959.

Zartman, R. E.: A Geochronologie Study of the Lone Grove Pluton from the Llano Uplift, Texas, J. Petrol., 5, 359-409, https://doi.org/10.1093/petrology/5.3.359, 1964.

Zimmermann, N. E. R., Vorselaars, B., Quigley, D., and Peters, B.: Nucleation of $\mathrm{NaCl}$ from Aqueous Solution: Critical Sizes, IonAttachment Kinetics, and Rates, J. Am. Chem. Soc., 137, 13352 13361, https://doi.org/10.1021/jacs.5b08098, 2015. 